Revue des patrimoines

$25 \mid 2014$

Le patrimoine de la Grande Guerre

\title{
Des monuments aux morts entre laïcité et ferveur religieuse : un patrimoine hors-la-loi ?
}

\section{Claude Dupuis}

\section{(2) OpenEdition \\ 12 Journals}

\section{Electronic version}

URL: http://journals.openedition.org/insitu/11326

DOI: 10.4000/insitu.11326

ISSN: 1630-7305

\section{Publisher}

Ministère de la Culture

\section{Electronic reference}

Claude Dupuis, « Des monuments aux morts entre laïcité et ferveur religieuse : un patrimoine hors-laloi ? », In Situ [Online], 25 | 2014, Online since 29 December 2014, connection on 25 June 2020. URL: http://journals.openedition.org/insitu/11326 ; DOI : https://doi.org/10.4000/insitu.11326

This text was automatically generated on 25 June 2020 .

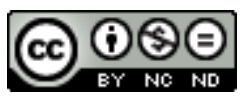

In Situ Revues des patrimoines est mis à disposition selon les termes de la licence Creative Commons Attribution - Pas d'Utilisation Commerciale - Pas de Modification 4.0 International. 


\title{
Des monuments aux morts entre laïcité et ferveur religieuse : un patrimoine hors-la-loi?
}

\author{
Claude Dupuis
}

\section{Des monuments pour se souvenir}

1 Les monuments aux morts revêtent deux fonctions principales: ils sont à la fois la tombe symbolique de ceux qui ont défendu la Nation et ils désignent un lieu des commémorations publiques. Dans ses formes les plus élémentaires mais très usitées de la stèle ou de l'obélisque, peu, voire aucun élément de nature artistique donc esthétique n'interfère entre le monument et ceux qui se souviennent. La seule présence des noms des disparus impose une certaine neutralité du message délivré par l'objet lui-même. La présence du soldat de bronze, issu des Établissements métallurgiques Durenne, des fonderies du Val d'Osne ou d'ailleurs, marque une étape vers une signification ou un message plus explicite délivrés par les commanditaires aux populations survivantes. Même si à l'exemple des modèles Poilu ou Résistance inventés par Charles-Henri Pourquet ou du Poilu victorieux créé par Eugène Bénet, sculpteur d'origine dieppoise, et reproduits en série, un seul et unique message semble être diffusé sur le territoire, les variations possibles dans les attributs ou les combinaisons des différents modèles marquent une volonté de "personnalisation » lorsqu'il ne s'agit pas de démontrer ostensiblement une aisance financière particulière en s'offrant les "options". L'exemple de Sommevoire en Haute-Marne est sans doute, au-delà de la volonté de commémorer la mémoire de "ses enfants morts pour la France ", à envisager comme une démonstration du savoir-faire de la fonderie implantée dans le village (fig. 1). Le monument réunit deux figures emblématiques des Établissements métallurgiques: le Poilu mourant de Jules Déchin dans sa version grand modèle et le déjà cité Poilu victorieux d'Eugène Bénet ${ }^{1}$. 
Figure 1

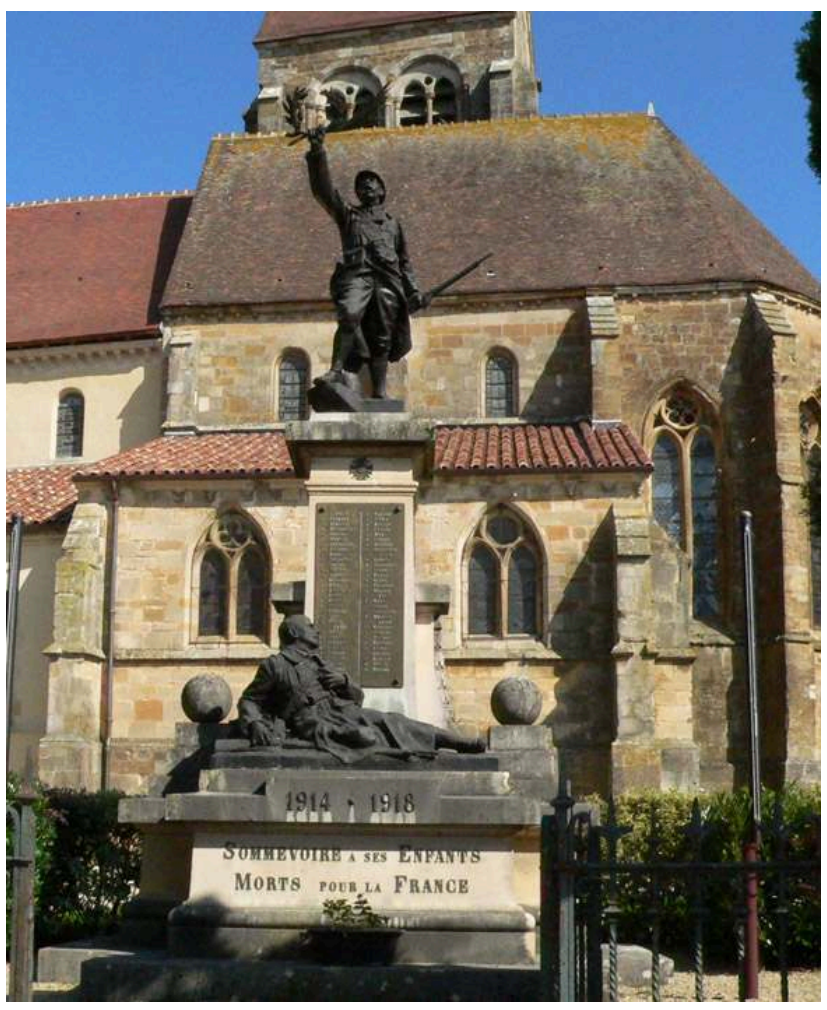

Monument aux morts de Sommevoire (Haute-Marne).

Phot. Dupuis, Claude. (C) Dupuis, Claude, 2010.

2 Figurées ou non, ces productions d'art ne doivent obéir qu'à une seule règle, celle de la laïcité, dès lors qu'elles sont implantées dans l'espace public. Depuis 1905, la loi de Séparation des Églises et de l'État et son article 28 stipulent qu'

il est interdit, à l'avenir, d'élever ou d'apposer aucun signe ou emblème religieux sur les monuments publics ou en quelque emplacement public que ce soit, à l'exception des édifices servant au culte, des terrains de sépulture dans les cimetières, des monuments funéraires, ainsi que des musées ou expositions ${ }^{2}$.

Tout le reste n'est que l'expression des désirs, des ressentiments, des convictions et des moyens financiers mis en œuvre par les commanditaires pour commémorer ceux qui ont perdu la vie au combat : " Les conseils municipaux de l'après-guerre se trouvèrent placés entre les convictions religieuses de la plupart des familles et l'idéologie laïque de la $\mathrm{III}^{\mathrm{e}}$ République. Cette dernière voulait des monuments qui ne rappellent en rien la pratique religieuse ${ }^{3} »$.

Dans son ouvrage Les Monuments aux Morts ${ }^{4}$, Annette Becker rappelle qu'il fut souvent fait appel à des figures féminines pour les monuments figurés. Principalement utilisées dans l'iconographie comme symboles ou allégories, d'autres sculptures présentent des femmes dans leur rôle de mère, de fille ou de veuve de soldats tombés pour la France. Si l'auteur évoque aussi les rapports des familles ainsi que des sculpteurs eux-mêmes à la religion et en particulier au catholicisme, elle ne revient pas directement sur la présence à travers les monuments aux morts d'une iconographie religieuse dans l'espace public français. À la fin de la Première Guerre mondiale, la séparation de l'Église et de l'État est encore jeune et ne semble pas être scrupuleusement respectée. Alors que nombre d'exemples présentés dans l'ouvrage d'Annette Becker se trouvent 
dans des espaces partiellement publics, des cimetières ou des chapelles, d'autres monuments font, dans l'espace communal, plus ou moins ouvertement référence à des thèmes religieux comme la Mater Dolorosa ou la Pietà.

5 Les différents monuments retenus ici afin de documenter la diversité des possibilités de conserver ou d'introduire du religieux dans l'espace public font appel à des figures féminines, qu'elles soient isolées ou accompagnées de personnages masculins. Dans un premier temps, ceux qui font directement référence à des motifs religieux seront présentés : les monuments de Beauvais dans l'Oise, de Saint-Nicolas-d'Aliermont en Seine-Maritime et de Montreuil-sur-Mer dans le Pas-de-Calais, tous trois de la main du sculpteur beauvaisien Henri Gréber, reprennent le motif de la descente de croix ou de la piéta. Si ce registre se retrouve assez souvent, les sculpteurs font néanmoins preuve d'originalité et d'inventivité dans son traitement: c'est à ce titre qu'ont aussi été retenus les monuments de Mazan dans le Vaucluse, de Chaulnes dans la Somme et de Louhans en Saône-et-Loire. Alors que le monument de Friville-Escarbotin fait écho au monument aux morts de la paroisse de la cathédrale d'Amiens dans le même département de la Somme, il est aussi à rapprocher des exemples précédents par l'adoption d'une iconographie au fondement religieux immédiatement reconnaissable. C'est une variation autour des thèmes du gisant et de la mise au tombeau. Dans un autre registre, il n'est pas rare de trouver des figures féminines en costume local ou régional sur les monuments aux morts mais certains allient tradition régionale et allusion au monde religieux, comme à Ibos, dans les Hautes-Pyrénées. Enfin, les principes d'une implantation à la frontière des espaces publics et religieux seront démontrés grâce aux monuments d'Escoublac (Loire-Atlantique) ${ }^{5}$ et de Sillery (Marne).

\section{Recueillir le soldat gisant ou agonisant : la pietà}

6 Le modèle très diffusé du soldat agonisant créé par Jules Déchin dès 1919 a servi de base à des compositions diverses, combinant figure couchée et figure en pied dans une composition triangulaire. Associé au Coq de Bénet à Sissonnes (Aisne) ou au Poilu victorieux du même sculpteur à Sommevoire ou à un Christ en croix dans le cimetière de Neuville-Saint-Vaast (Pas-de-Calais), le Poilu agonisant est accompagné de figures féminines à Chaulnes (fig. 2), Louhans et Mouy (Oise). 
Figure 2

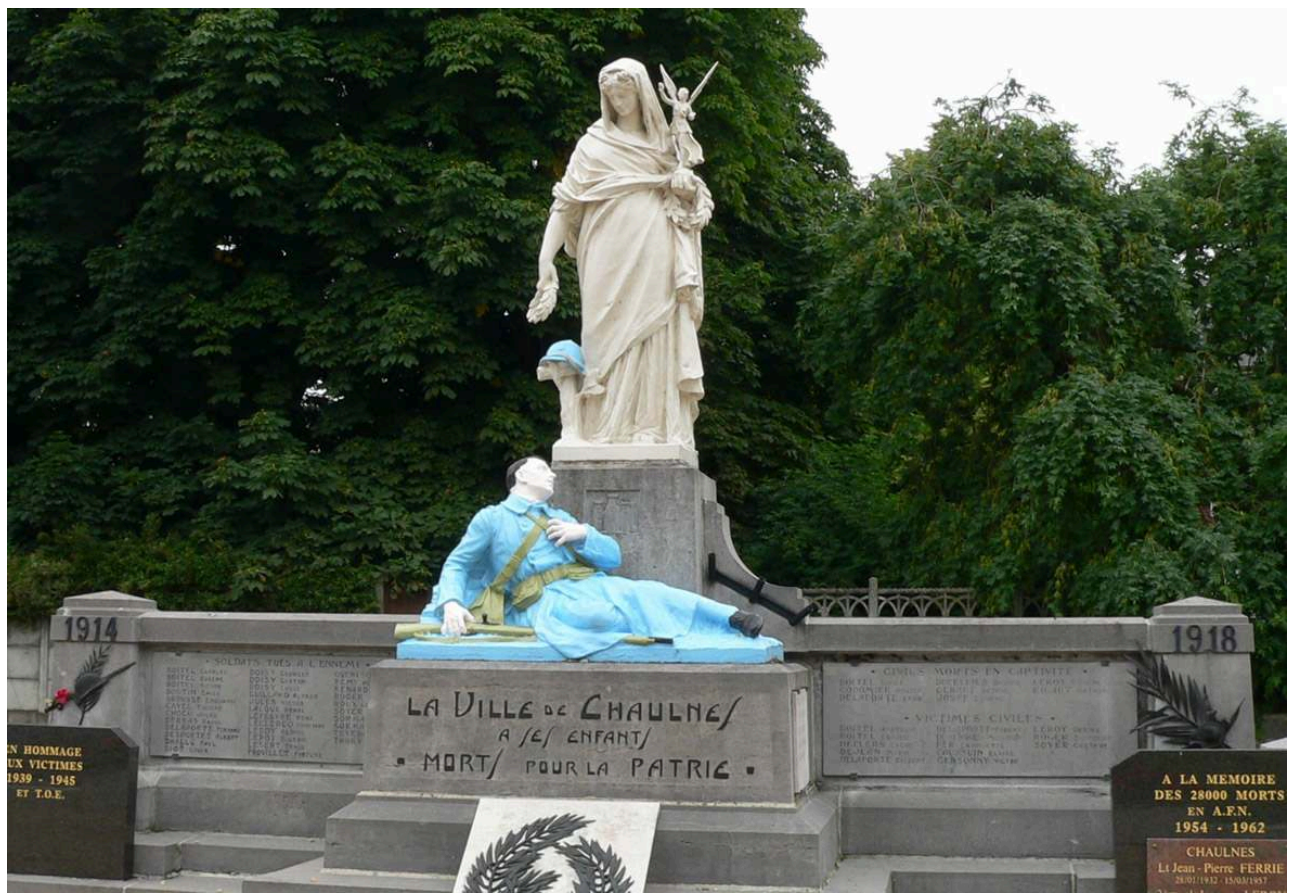

Monument aux morts de Chaulnes (Somme).

Phot. Dupuis, Claude. (c) Dupuis, Claude, 2013.

7 Quelques différences entre ces versions, hormis celle des matériaux (fonte dans la Somme et pierre en Saône-et-Loire), existent. Le monument de Chaulnes est surmonté d'une statue à l'antique tenant dans sa main gauche une petite figure de victoire ailée ${ }^{6}$. Alors que la Nikê tend une couronne de laurier vers le ciel, la seconde figure féminine semble vouloir en déposer une autre sur le soldat agonisant à ses pieds. Il ne s'agit pas ici d'une représentation d'une Athéna mais bien plus tôt d'une allégorie de la commune, voire de la nation?

Figure 3

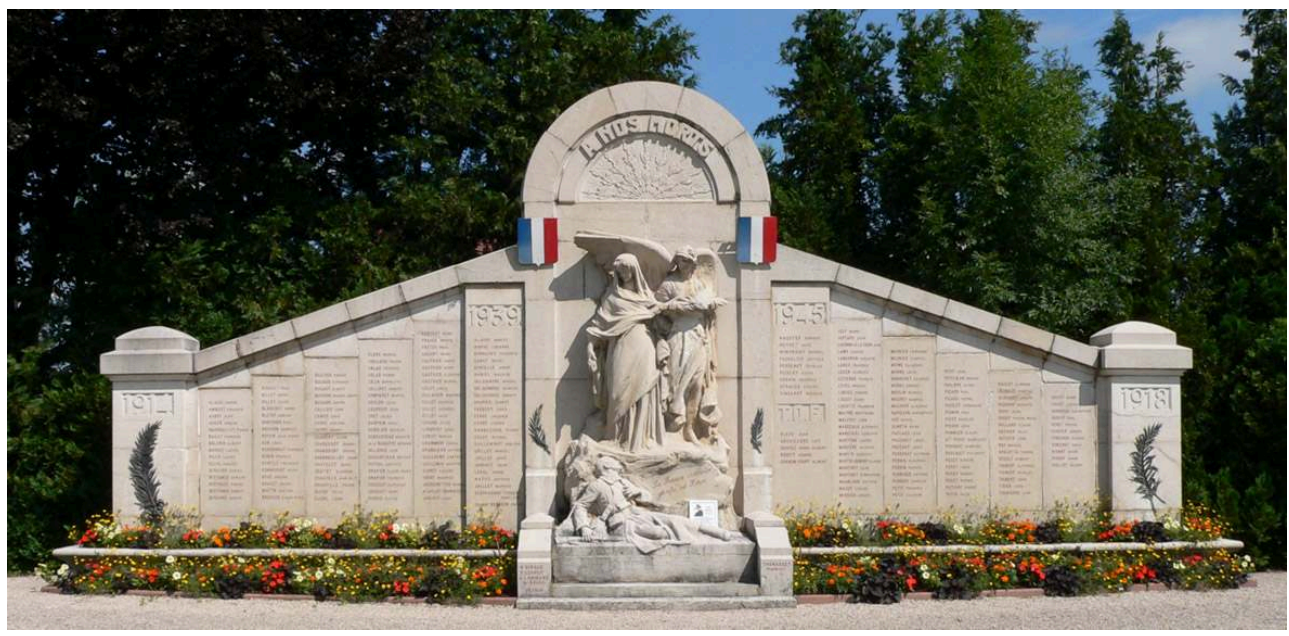

Monument aux morts de Louhans (Saône-et-Loire).

Phot. Dupuis, Claude. (c) Dupuis, Claude, 2013. 
C'est ce qui ressort par analogie avec le monument de Louhans où la Nikê est de même taille que l'allégorie de la France, tout en la protégeant de ses ailes (fig. 3). L'inscription «La France victorieuse glorifie ses héros » placée sur le bloc soutenant les deux figures féminines juste au-dessus du soldat écarte toute ambiguïté dans l'interprétation du sujet. L'absence de contact entre les deux groupes sculptés et la référence à l'antique différencie les monuments de Chaulnes et de Louhans de ceux de Beauvais, SaintNicolas-d'Aliermont, de Montreuil-sur-Mer ou encore de Mazan. La Nikê ou victoire ailée proposée par Henri Gréber à Beauvais tient la dépouille nue d'un soldat dans ses bras (fig. 4).

Figure 4

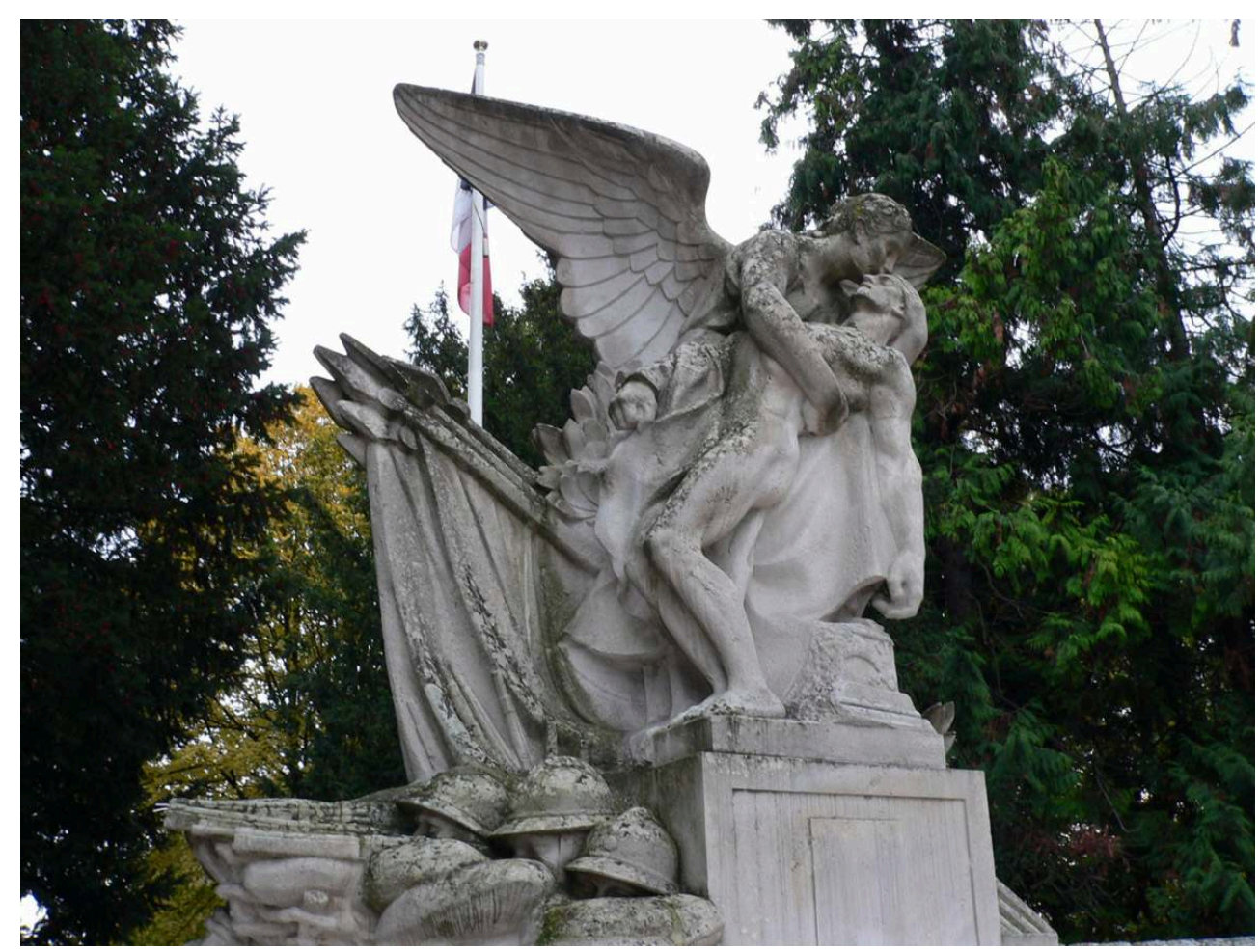

Monument aux morts de Beauvais (Oise).

Phot. Dupuis, Claude. (c) Dupuis, Claude, 2009.

Le corps de l'homme est maintenu dans une position quasi verticale, ce qui rapproche cette représentation plus de celle de la descente de croix que de la pietà à proprement parler. La figure ailée retient le corps défunt qui plie sous son propre poids alors que dans les exemples suivants, le corps inanimé semble avoir été débarrassé de cet aspect purement physiologique, donc humain. C'est un motif proche de celui du monument de Montreuil-sur-Mer dans le Pas-de-Calais. Là, le corps est encore en partie vêtu de la capote, le lourd manteau de soldat. Seule l'épaule gauche apparaît. Déposant le corps agonisant sur sa cuisse, la figure ailée embrasse sur le front le soldat qui tente de se retenir au drapeau. Avec les palmes, les roses, les drapeaux, le monument de SaintNicolas-d'Aliermont reprend la composition employée par Henri Gréber à Beauvais et Montreuil-sur-Mer (fig. 5). 
Figure 5

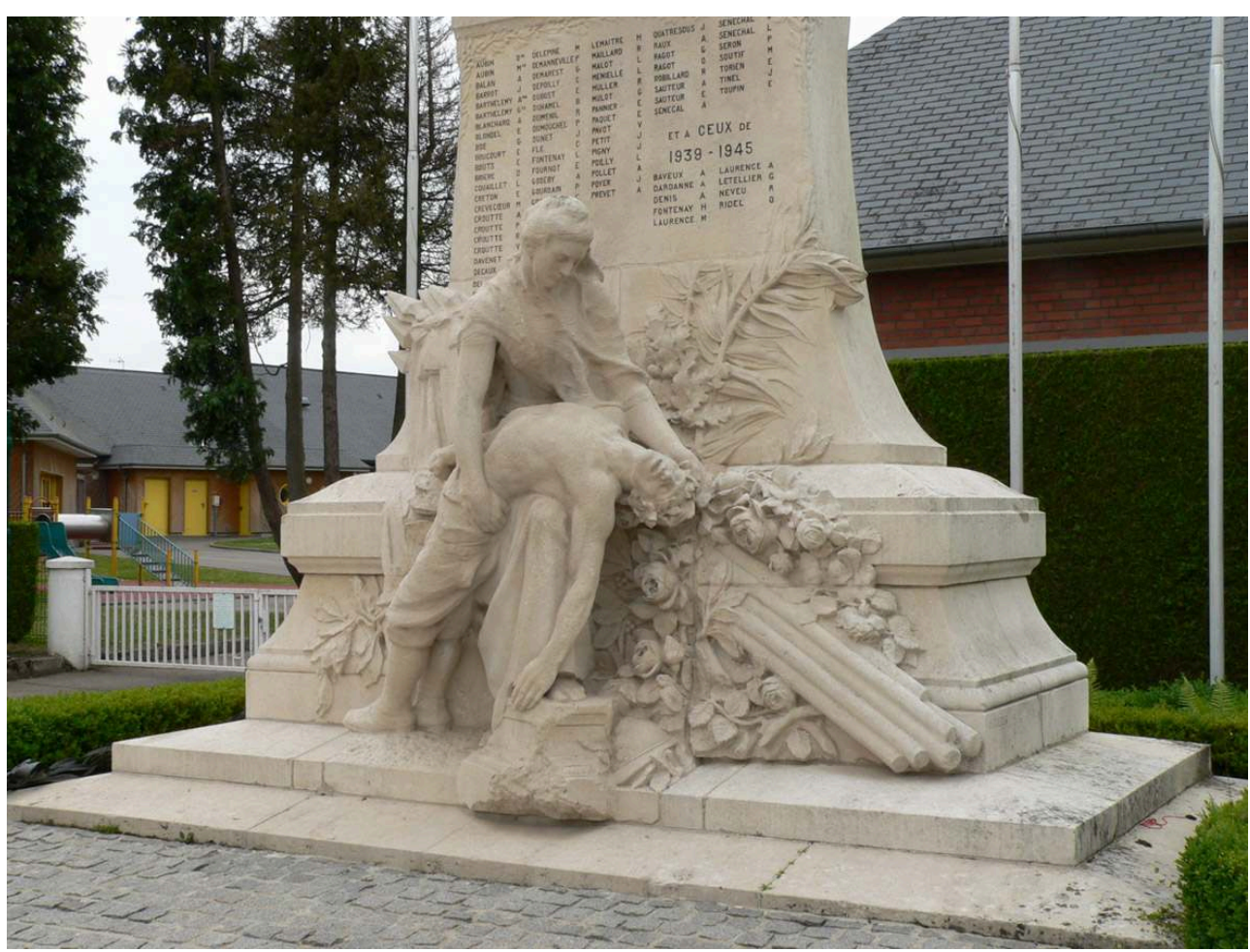

Monument aux morts de Saint-Nicolas-d'Aliermont (Seine-Maritime)

Phot. Dupuis, Claude. (c) Dupuis, Claude, 2013.

10 Le soldat n'est qu'à moitié dévêtu. Alors que dans les deux exemples précédents, le corps était maintenu plus ou moins verticalement, il s'enroule maintenant autour de la cuisse gauche de la figure féminine, habillée à la mode contemporaine. Le voile léger qui l'enveloppe la place dans un registre allégorique différent mais est à interpréter comme signe de deuil. Le modèle retenu par le sculpteur beauvaisien est celui d'une personne encore jeune. Il est difficile d'imaginer un rapport de descendance ou d'ascendance entre les deux figures du monument. Néanmoins les axes de composition, la position du corps masculin sur la cuisse de la figure féminine renvoient aux différentes Vierges de pitié qui jalonnent l'histoire de la sculpture mais aussi celle de l'art en général. Si l'interprétation religieuse de cet ensemble de Saint-Nicolasd'Aliermont est réservée à un public initié, d'autres exemples font référence beaucoup plus directement aux piéta traditionnelles. Le monument de Mazan, «composé d'un large piédestal surmonté d'un groupe sculpté représentant une femme agenouillée qui tient un soldat mort dans ses bras ${ }^{8} »$ illustre ce phénomène (fig. 6). 
Figure 6

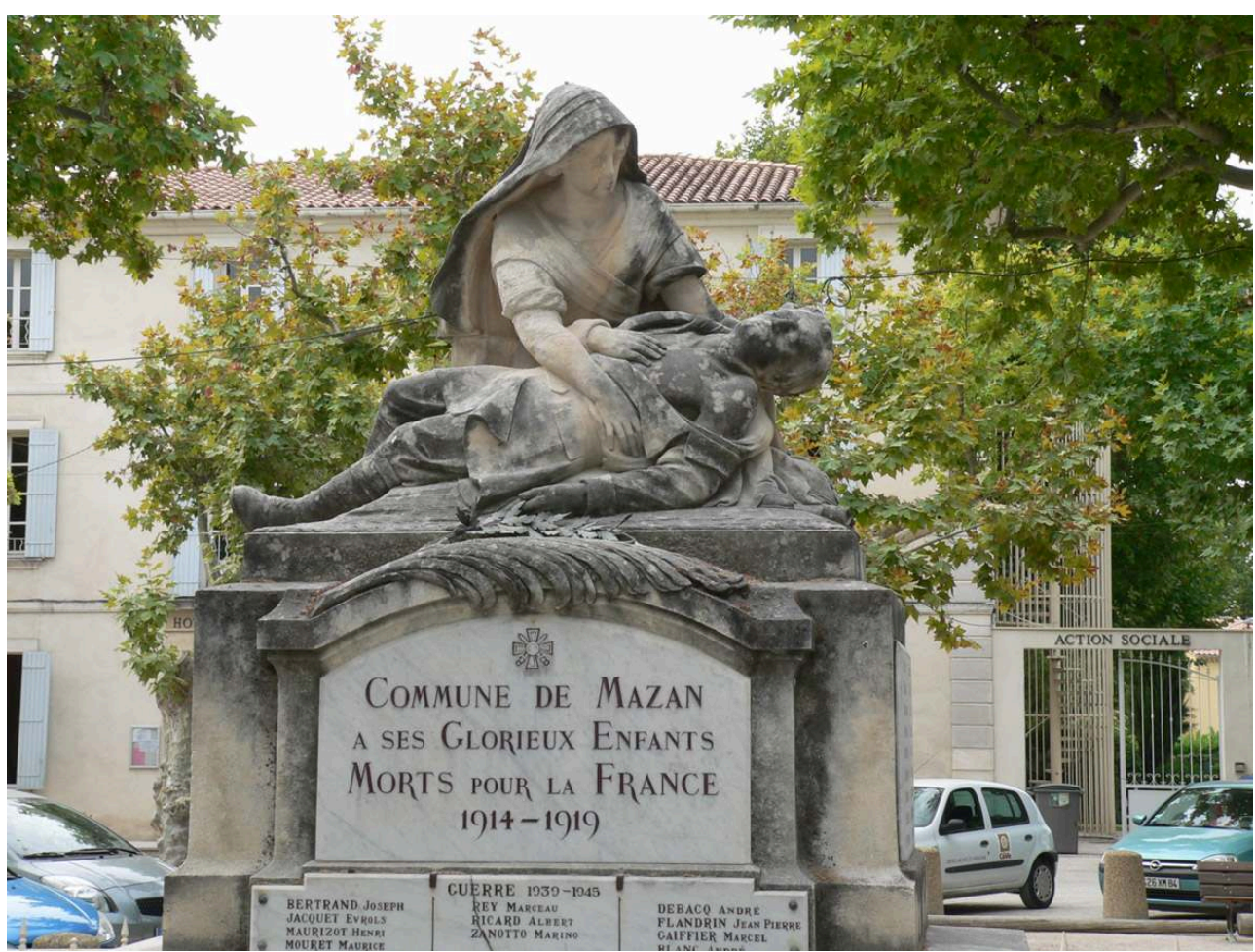

Monument aux morts de Mazan (Vaucluse).

Phot. Dupuis, Claude. (c) Dupuis, Claude, 2009.

11 Le sculpteur Noël Ruffier a représenté, au-dessus du parallélépipède de pierre calcaire sur lequel sont apposées des plaques de marbres gravées avec les noms des "glorieux enfants morts pour la France 1914-1919 ", un soldat aux yeux déjà clos, la main gauche repliée sur sa poitrine, que la femme derrière lui laisse lentement glisser vers le sol, tout en lui maintenant de ses mains le torse et la tête. Ici aussi, l'épaule du poilu défunt est dénudée, dévoilant son thorax. La femme ne parait pas plus âgée que le soldat comme il se devrait pour une mère éplorée, à moins qu'il ne s'agisse là d'une allégorie de la religion, à l'instar de la sculpture du projet d'Edme Bouchardon pour le tombeau du cardinal de Fleury aujourd'hui conservée au Louvre ${ }^{9}$. La croix portée au cou par la femme, placée dans le triangle formé par le croisement de son vêtement, plaide pour une telle interprétation, tout autant que le long capuchon qui la recouvre de la tête au pied, amenant l'association avec les représentations courantes du Stabat Mater. Le truchement qui consiste à interpréter quelquefois l'allégorie féminine comme celle de la patrie ou de la nation en lieu et place de la Vierge ou de la religion et définir ainsi une "pietà laïque " ne peut être appliqué au monument de Mazan et peut-être pas davantage ailleurs. La France a été, depuis le Vœu de Louis XIII en 1638, tout entière consacrée à Dieu par l'intercession à Marie. Dans l'inconscient collectif, les quinze ou vingt premières années de laïcité n'ont probablement pas effacé ce patronage. Dans de nombreuses représentations du Vœu, le roi est au pied de la croix, quelquefois aussi accompagné de son épouse Anne d'Autriche, aux côtés d'une Vierge le corps du Christ dans ses bras ou reposant sur ses genoux ${ }^{10}$. En 1860 au Puy-en-Velay est inaugurée une statue monumentale de Notre-Dame-de-France. L'ouvrage réalisé à partir des canons récupérés à l'ennemi à la bataille de Sébastopol relie ainsi les soldats français au culte marial. À noter aussi que le cardinal de Richelieu aurait suggéré à Louis XIII en 1636 
l'offrande d'une lampe à Notre-Dame de Paris afin d'obtenir le soutien de la future patronne de la France lors de la guerre contre l'Espagne. La France et ses soldats ont donc entretenu longtemps des liens étroits avec la Vierge et le culte marial. L'analogie du sacrifice du Christ, fils de Marie, avec celui des soldats, fils de la Nation, permit quant à elle la transcription du modèle de la pietà à celui du monument aux morts, tel qu'à Mazan. Si le monument commémoratif du Vaucluse fait directement référence au religieux, par le détail déjà signalé plus haut de la croix suspendue au cou de la figure féminine, d'autres réalisations ne reprennent que la composition en triangle et l'association d'une femme soutenant un mourant. Le monument aux morts de SaintPée-sur-Nivelle (Pyrénées-Atlantiques) n'est pas une variation autour du thème de la pietà comme dans d'autres communes françaises ${ }^{11}$ mais une copie de la Pietà de MichelAnge conservée dans la basilique Saint-Pierre de Rome. Son caractère religieux ressort d'autant plus que le monument est à proximité immédiate de l'église de la commune, placée sous le patronage de saint Pierre, et que le groupe sculpté a été déposé sous une croix. C'est une disposition semblable au monument d'Apach en Moselle. Si, sur la presque totalité du territoire français, le caractère légal de certains monuments pourrait peut-être être contesté du fait de la présence de signes religieux dans l'espace public, le régime concordataire en Alsace et en Moselle en rend l'appréciation plus difficile car il n'est pas question ici d'une séparation stricte de l'État et de l'Église ${ }^{12}$. Les pietà d'Apach ou de Metz font appel à l'universalité de la religion. Dans ces régions partagées entre deux nations, au gré des victoires, les habitants sont passés en 1871 sous le giron allemand avant de retrouver la nationalité française après 1918. Annette Becker a proposé une analyse du monument messin allant dans ce sens :

Le monument de Metz est tout à fait exemplaire de la représentation du deuil et de l'ambiguïé de la commémoration dans l'Alsace et la Moselle rendues à la France en 1918. La mère du combattant, nouvelle Vierge Marie, retrouve son fils, le tient dans ses bras, le monument est devenu pietà ou mater dolorosa. Mais si le combattant a remplacé le Christ sur le champ de bataille, il portait un uniforme. Ici, il gît nu. Comment en effet reconnaître un Allemand d'un Français, sans l'uniforme ?13

Le monument conservé a perdu trois reliefs, celui du dessus qui représentait une famille composée de parents entourant une femme plus jeune allaitant un enfant reposant sur ses genoux, et les deux reliefs latéraux, deux figures de poilus. En (re)prenant la ville en 1940, les troupes allemandes ont supprimé les motifs trop français, ne conservant que celui de la pietà, sans doute pour les mêmes raisons que celles qui avaient mené au choix de ce motif en 1935. Cet exemple montre aussi la persistance de l'allusion au religieux puisqu'édifié trente années après la promulgation de la loi sur la Séparation des Églises et de l'État et/ou le poids du régime concordataire évoqué plus avant. 
Figure 7

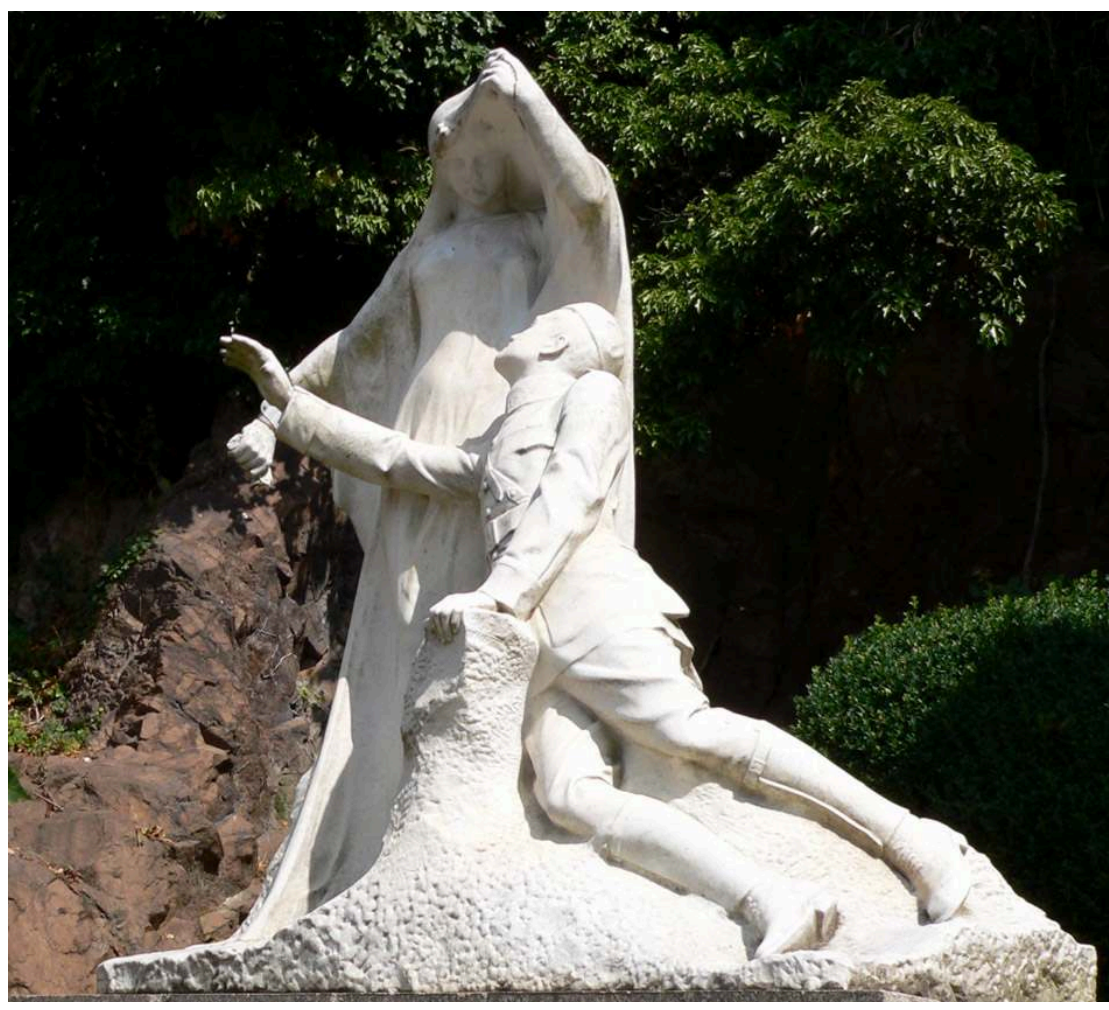

Monument aux morts de Thann (Haut-Rhin).

Phot. Dupuis, Claude. (c) Dupuis, Claude, 2013.

13 Érigé en 1920, le monument au sous-lieutenant Henri Chardon par Paul Gasq, à Thann (Haut-Rhin) (fig. 7) ne commémore pas officiellement les soldats de la ville disparus lors de la Première Guerre mondiale ${ }^{14}$. Mais en l'absence d'un autre monument aux morts ${ }^{15}$ et par sa composition d'après un modèle de pietà, le soldat Chardon, revêtu de l'uniforme de poilu, tentant de se relever, il a pu répondre, de manière non officielle, à ce besoin de commémoration. À Briey, en Meurthe-et-Moselle, à une trentaine de kilomètres au nord-est de Metz, le monument aux morts signé Maxime Real del Sarte ${ }^{16}$ s'apparente aux diverses réalisations retenues jusqu'ici. Du relief de bronze se détache un soldat agonisant enroulé dans un drapeau, les mains jointes, soutenu par une Jeanne d'Arc nimbée devant une croix et désignant de son bras gauche une représentation de la cathédrale de Strasbourg. Avec la présence de tous ces symboles, le caractère religieux du monument est indéniable ${ }^{17}$. Il existe une autre version en pierre de ce relief en Poitou-Charentes, à Sommières-du-Clain dans la Vienne. Le choix même du sculpteur Maxime Real del Sarte, catholique, nationaliste, monarchiste et fondateur des Compagnons de Jeanne d'Arc ${ }^{18}$, révèle les intentions des commanditaires. Une composition analogue se retrouve aux monuments aux morts de Langogne (Lozère), de Guéthary (Pyrénées-Atlantiques) et du cimetière de Saint-Martin-aux-Buneaux (SeineMaritime). Real del Sarte a ici repris la figure d'une femme casquée, devant une croix, au bras gauche tendu vers le ciel, soutenant un soldat mort aux mains jointes. Le groupe sculpté est posé sur un piédestal sur lequel sont apposées les plaques gravées des noms des « enfants de Saint-Martin aux Buneaux morts pour la France ». Une autre série de monuments aux morts réalisée par Real del Sarte associe un soldat mort, les mains jointes là encore, enveloppé dans un linceul, à une figure de femme, le voile 
maintenu par une couronne de laurier semblable à celle qu'elle s'apprête à déposer sur le corps du héros ${ }^{19}$. Si le motif de la pietà est encore présent, le sculpteur laisse ici peu à peu la place à un autre genre de représentation religieuse utilisée pour des monuments, celui de la mise au tombeau ou du saint-sépulcre. L'association d'un soldat mort ou agonisant et d'une figure féminine, ailée ou non, voilée ou non, accompagnée à l'occasion de signes religieux ostentatoires et la forme triangulaire de la composition renvoient indubitablement au modèle religieux de la pietà. Souvent, les réalisateurs de ces groupes sculptés se sont efforcés de laïciser complètement le motif, usant de figures civiles comme Alphonse Muscat pour le monument de Lagnieu (Ain) ${ }^{20}$, d'allégorie ou de référence à l'antique. D'autres ont fait le choix de présenter deux versions, l'une laïque, l'autre religieuse, du Stabat Mater Dolorosa sur un seul et unique monument, comme à Aixe-sur-Vienne (Haute-Vienne) ou à Bois-Grenier (Nord) ${ }^{21}$. Là, le groupe de trois figures est dominé par une femme qui tient dans sa main gauche celle du soldat agonisant et a posé son autre main sur l'épaule droite d'une femme voilée, agenouillée, embrassant le front du mourant, comme au monument aux morts, une pietà intitulée Dernier baiser de la Patrie, d'Alfred Boucher inauguré en 1921 à Nogent-sur-Seine (Aube) ${ }^{22}$. À Bois-Grenier, le corps du militaire est déposé sur la cuisse de la femme au chignon, la tête renversée, à la manière du monument de Saint-Nicolas-d'Aliermont. D'autres réalisations du sculpteur Maurice Ringot à Crespin ${ }^{23}$ et à Don dans le Nord permettent une interprétation du groupe de Bois-Grenier. La même femme âgée à l'arrière-plan, les bras déployés telle une sainte Ursule ou Vierge de miséricorde, protège une femme voilée plus jeune accompagnée d'un enfant en bas-âge. L'inscription gravée "Aux veuves et orphelins victimes de guerre" offre une interprétation à ceux qui viennent se recueillir.

Le monument d'Aixe-sur-Vienne, avec ses deux groupes sculptés, est dédié à NotreDame d'Arliquet ${ }^{24}$. C'est la sculpture de cette Vierge de pitié qui a servi de modèle au sculpteur Luchetti pour la pietà "religieuse " au-dessus du monument aux morts consacré en août $1924^{25}$. En dessous, une pietà «laïcisée » est composée d'un soldat encore assis soutenu par le bras d'une figure féminine placée derrière lui et qui indique de son bras droit la petite sculpture déjà mentionnée. Avec à l'origine deux doigts levés, l'index et le majeur, la femme bénissait le soldat tel un Salvator Mundi, soutenue par la sculpture de l'allégorie de la France chrétienne, une croix dans la main gauche, une couronne de laurier dans l'autre.

\section{Travailler, prier et pleurer : un credo féminin}

Les variations autour du modèle de la pietà ou de sa version plus large, celle de la déploration du Christ, témoignent de la vivacité de la ferveur religieuse dans la France $\mathrm{du}$ premier quart du vingtième siècle ${ }^{26}$. Toutes sont basées sur la figure du soldat agonisant accompagnée d'une allégorie (Victoire, France...), d'une femme voilée, symbole du veuvage ou bien encore d'une figure ailée (ange ou Nikê) à l'exception du monument de Préveranges, dans le $\mathrm{Cher}^{27}$. Placé sur un piédestal, un soldat debout retient un second poilu blessé qui s'effondre. C'est à notre connaissance, avec le monument de Billom, dans le Puy-de-Dôme, un des rares exemples composés uniquement de figures masculines dont l'inspiration pourrait être une Vierge de pitié28. Il s'agit bien plus que d'une analogie entre ces compositions quelquefois profanes et l'iconographie chrétienne. Les différentes terminologies rencontrées (pietà laïque, 
profane ou encore républicaine) renvoient toutes au modèle traditionnel issu du domaine religieux. Les monuments témoignent du lourd tribut payé par les femmes durant la Première Guerre mondiale. Il est donc compréhensible que les sculpteurs et architectes aient désiré représenter la douleur qu'elles ont ressentie. Le nombre de modèles de femme dans la statuaire publique jusqu'au début $\mathrm{du} \mathrm{XX}^{\mathrm{e}}$ siècle est assez restreint, celui de femmes éplorées encore plus. Quelques monuments aux morts de la guerre de 1870 ont fait appel, à côté de scènes de combat, aux allégories de la France ou de la Victoire, comme à Troyes (Aube), Fontenoy-sur-Moselle (Meurthe-et-Moselle), Saint-Étienne (Loire) ${ }^{29}$, mais peu ont représenté les Françaises. Même s'il reste difficile de mettre en lumière des généralités sur les monuments aux morts, compte tenu à la fois du nombre important de réalisations et de leur diversité, une tendance se dessine néanmoins : les sculpteurs, en particulier les nouveaux venus, ont délaissé les scènes de combat, conduisant à un certain dépouillement des monuments après la guerre de 1914-1918, comparé aux précédents, et ont attiré l'attention du public sur les figures, souvent très statiques. C'est par ailleurs paradoxal. Les monuments érigés après la défaite de 1870 qui sont conservés paraissent fréquemment plus expressifs, plus " vivants » que ceux édifiés après la victoire de 1918, celle-ci ayant été acquise au prix élevé de la disparition de plus d'un million d'hommes (fig. 8).

Figure 8

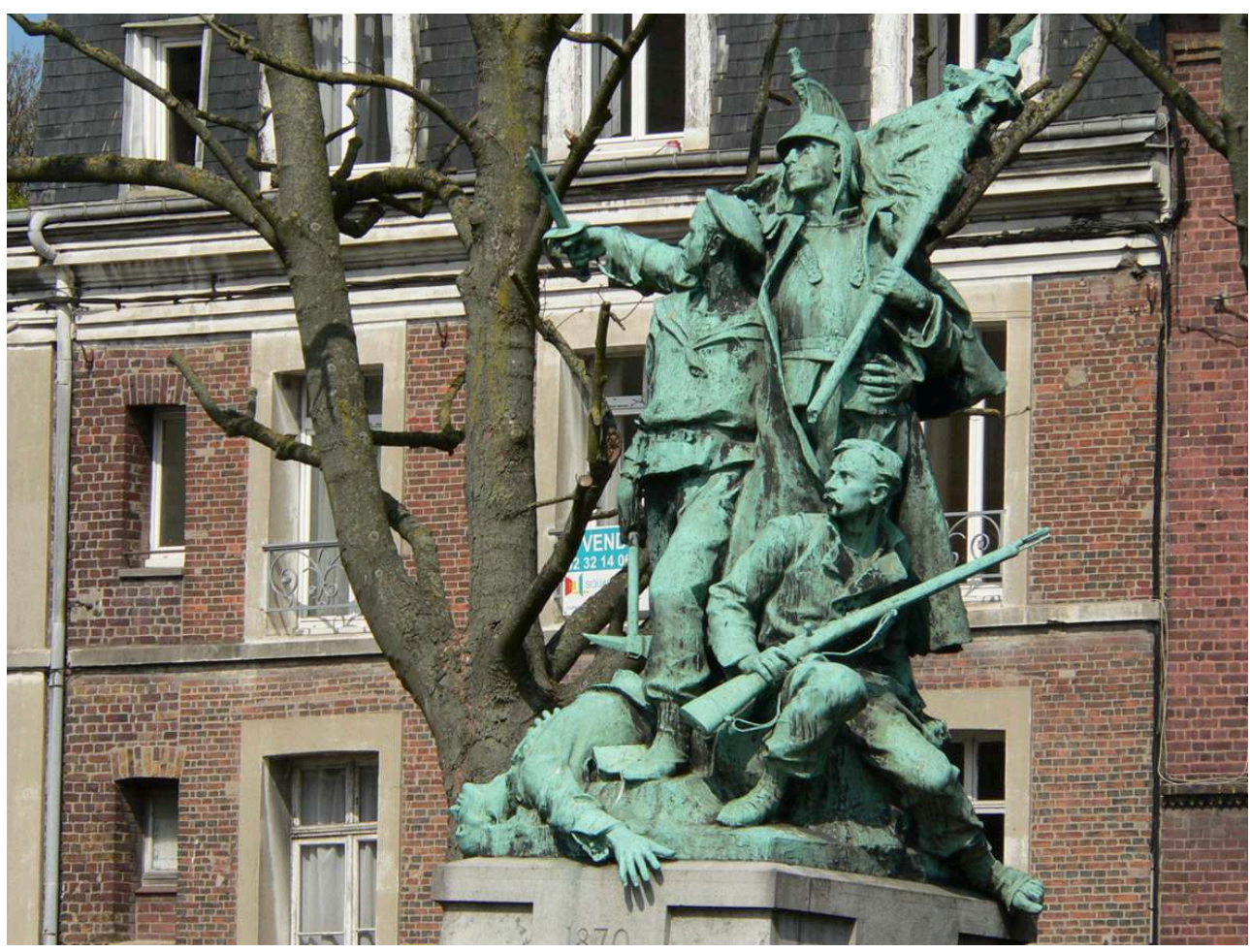

Monument aux morts de 1870, Dieppe (Seine-Maritime).

Phot. Dupuis, Claude. (C) Dupuis, Claude, 2011.

Le manque de références iconographiques et le nombre croissant de commandes privées de monuments funéraires depuis le milieu du XIX siècle a pu conduire les sculpteurs et concepteurs des monuments aux morts à se tourner vers cette imagerie religieuse. Un contingent important de monuments aux morts sculptés paroissiaux à l'intérieur des églises sont des pietà, anciennes ou non. Les coiffes ou costumes 
régionaux des figures féminines témoignent de la volonté de « célébrer » celles qui ont contribué à maintenir le pays en fonctionnement en l'absence des hommes et des fils partis au front. Un des reliefs du monument de La Côte-Saint-André, en Isère, représente une femme en train de labourer. À Simandre (Saône-et-Loire), la femme qui présente un enfant au poilu debout au-dessus d'elle porte à la ceinture un étui dans lequel repose une pierre à aiguiser, en référence à son implication dans les travaux agricoles. À quelques kilomètres de là, dans le même département, à Cuisery, Pierre Curillon a placé devant le piédestal soutenant un poilu ${ }^{30}$ une femme qui porte une gerbe de plantes céréalières dans son tablier (fig. 9).

\section{Figure 9}

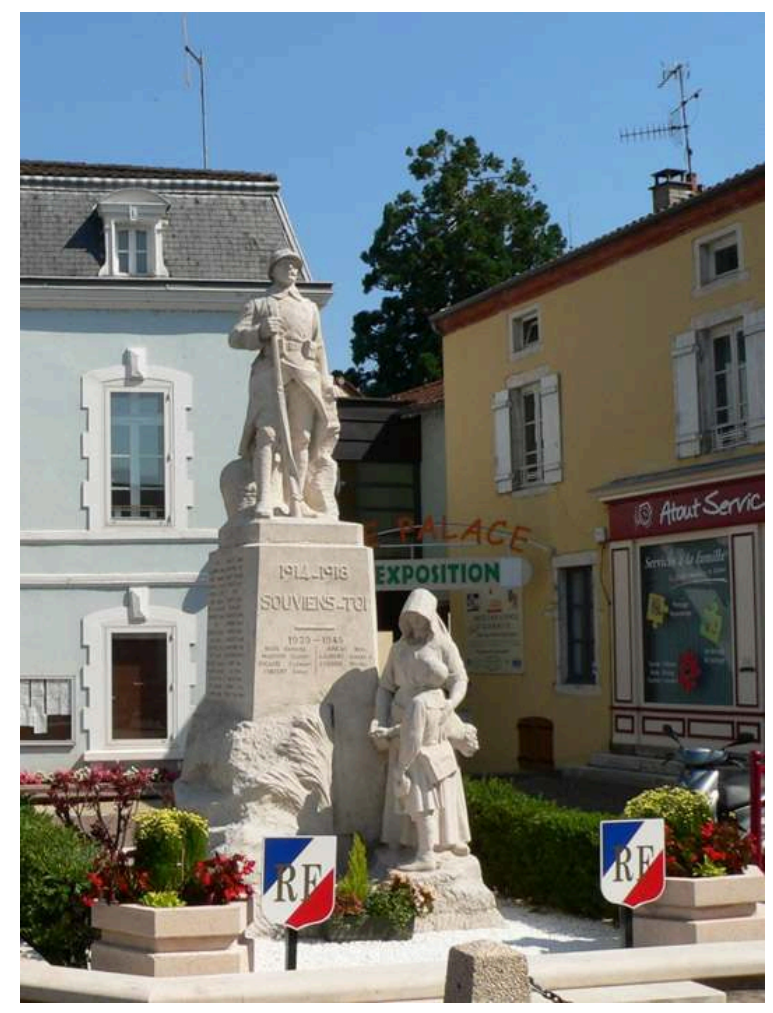

Monument aux morts de Cuisery (Haute-Saône).

Phot. Dupuis, Claude. (c) Dupuis, Claude, 2013.

C'est aussi dans cette recherche de représentation de la douleur féminine ou parentale qu'il faut inscrire les monuments faisant référence à la déploration du Christ et à sa mise au tombeau. Si à ce propos quelques réalisations de Maxime Real del Sarte ont déjà été évoquées ${ }^{31}$, deux réalisations $d u$ sculpteur Albert Roze permettent d'appréhender la présence du religieux dans la commémoration des «morts pour la Patrie ». Le sculpteur originaire d'Amiens a réalisé une trentaine de monuments aux morts dans le département de la Somme ${ }^{32}$, espaces publics, cimetières et édifices religieux inclus. La plupart d'entre eux ne sont que des représentations de poilus, quelquefois accompagnés de marins, un deuxième ensemble met en scène un couple mère/enfant. Enfin, cinq monuments se distinguent des autres par leur thématique ou leur forme : au Ronssoy, c'est un buste de poilu médaillé de la croix de guerre qu'a élevé Albert Roze ${ }^{33}$, dans le carré militaire du cimetière amiénois de Saint-Acheul, c'est une veuve éplorée assise devant un obélisque tronqué aux quatre faces en forme de croix $^{34}$, 
à Rollot ${ }^{35}$, le soldat embrasse une femme sur la joue ${ }^{36}$, et les deux derniers monuments se trouvent pour le premier, dans le collatéral sud de la cathédrale d'Amiens ${ }^{37}$ et le second, à Friville-Escarbotin ${ }^{38}$.

Figure 10

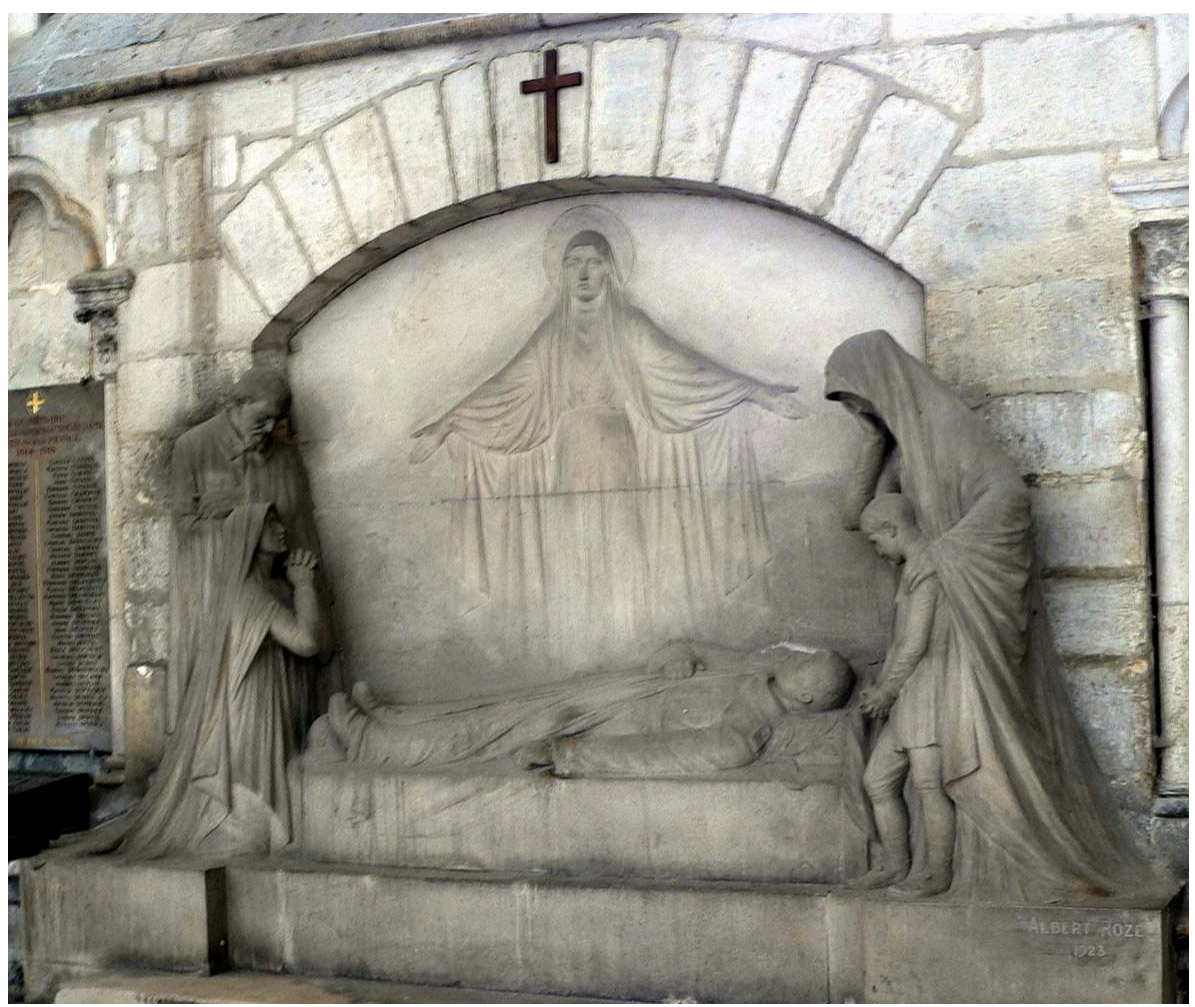

Monument aux morts de la paroisse Notre-Dame, dans la cathédrale d'Amiens (Somme).

Phot. Dupuis, Claude. (c) Dupuis, Claude, 2013.

Il s'agit de deux variations contemporaines du thème de la mise au tombeau. Le monument aux morts paroissial de l'église métropolitaine comporte cinq personnages qui entourent le corps du soldat défunt (fig. 10). Au fond de la composition, sous un enfeu moderne, Notre-Dame, patronne de la paroisse, représentée en léger relief, étend ses bras au-dessus du gisant au visage tourné vers l'est, c'est-à-dire vers le chœur, à l'image des sépultures de bronze des évêques Évrard de Fouilloy, décédé en 1222, et Geoffroy d'Eu, son successeur disparu en 1236, placées aujourd'hui au bas de la nef de la cathédrale amiénoise ${ }^{39}$. Le groupe de gauche, un homme debout vêtu d'une capote avec devant lui une femme voilée, agenouillée et les mains jointes s'adressant du regard à Notre-Dame, a été interprété comme les figures de parents ${ }^{40}$. Le visage de l'homme se distingue d'autres sculptures de pères signées Albert Roze par la présence d'une barbe ${ }^{41}$. Il s'apparente plus aux bustes de saint Vincent de Paul et de saint Ignace dans la basilique d'Albert, voire à celui de Charles-Albert Joseph Lecomte, évêque d'Amiens de 1921 à 1934, aujourd'hui dans la chapelle Notre-Dame-de-Pitié de la cathédrale, à moins qu'il ne s'agisse là d'un autoportrait. Le groupe de droite reprend une thématique plus courante chez Albert Roze, celle de la femme et l'enfant déjà déclinée en veuve et orphelin au monument aux morts du cimetière de Vignacourt inauguré en $1921^{42}$ ou bien encore à Fontaine-sur-Somme en $1922^{43}$. Le sculpteur a choisi 
d'agrémenter la figure féminine, sa main droite couvrant en partie son visage, d'une croix pendante à son cou, contrairement aux deux groupes déjà cités (fig. 11).

Figure 11

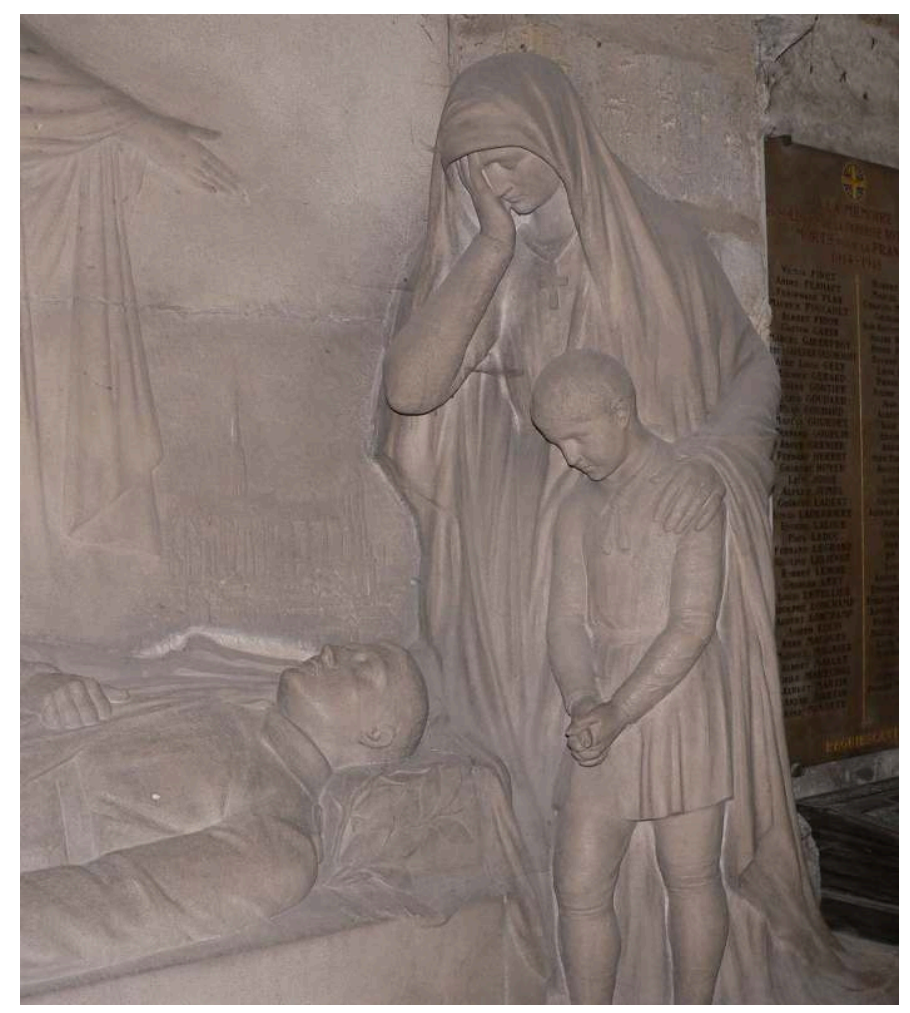

Monument aux morts de la paroisse Notre-Dame, dans la cathédrale d'Amiens (Somme). Détail du groupe sculpté de droite.

Phot. Dupuis, Claude. ( ) Dupuis, Claude, 2013

Roze semble donc ici respecter à la lettre la loi de 1905, ne faisant figurer des signes religieux que dans les lieux non publics. La même année, c'est-à-dire en 1923, il conçoit pour la commune de Friville-Escarbotin-Belloy un monument très proche de celui de la cathédrale d'Amiens. Destiné à être installé dans l'espace public, aucun signe religieux n'apparait sur le monument, même si son iconographie est directement issue de l'univers religieux : une mise au tombeau (fig. 12). 
Figure 12

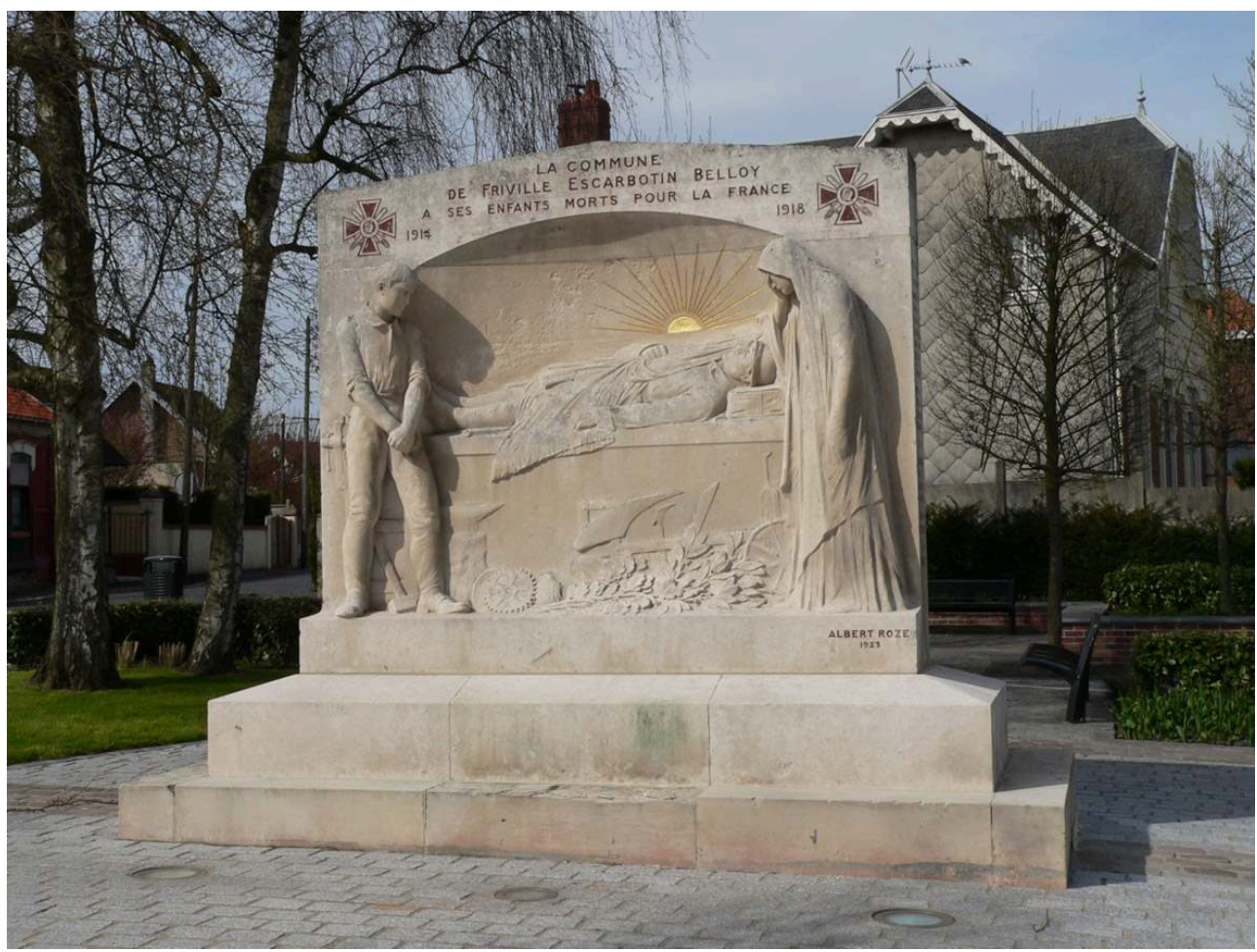

Monument aux morts de Friville-Escarbotin (Somme)

Phot. Dupuis, Claude. (c) Dupuis, Claude, 2013.

Le relief du soldat gisant, enroulé dans un drapeau, est placé dans un enfeu en cul-defour, devant lequel sont postés de part et d'autre un homme encore jeune à gauche, une femme à droite. Le corps du militaire repose sur un simple sarcophage de pierre, la tête posée sur sa besace. Alors que la figure féminine est une légère variation de la pleureuse de la cathédrale, la figure masculine reprend pour un personnage adulte l'attitude de l'enfant du groupe amiénois. Le garçon et le jeune adulte croisent leurs mains de la même manière et possèdent un port de tête similaire. Le décor au bas du sarcophage de pierre renvoie aux activités masculines, à gauche, et féminines à droite. La roue dentée, l'enclume, la masse et l'étau sont associés au travail de l'homme en bras de chemise pendant que les travaux agricoles, symbolisés par la charrue et son soc proéminent, font allusion à l'activité féminine en temps de guerre, comme pour le monument aux morts de La Côte-Saint-André (Isère) souvent cité à ce propos. Une gerbe de branches de chêne et de laurier est posée devant la charrue, comme déposée par la pleureuse. En plus de l'inscription et les deux croix de guerre gravées sur la face avant du monument, un dernier détail est à souligner : le soleil aujourd'hui restauré et étincelant. Si aperçu de loin il peut apparaître tel un nimbe, placé non pas près du visage mais au-dessus du thorax du soldat, médaillé de la croix de guerre, le soleil placé sur la droite de la cavité symbolise le renouveau, la reprise de la vie après le conflit ${ }^{44}$.

21 Les «mises au tombeau » sont bien moins nombreuses que les modèles dérivés des pietà, un motif iconographique quant à lui particulièrement répandu dans les monuments commémoratifs paroissiaux à l'intérieur des édifices religieux. Quelquefois, comme à Soubès dans l'Hérault ${ }^{45}$, c'est l'allure générale du monument qui de prime abord évoque le motif de la mise au tombeau, même si le sujet est plutôt une veillée du soldat mort. Paul Dardé a sculpté là dans un « cénotaphe ouvert sur la face principale et 
abritant un groupe en haut relief en pierre de Lens ", un soldat gisant et une femme apposant ses deux mains sur son thorax. C'est le placement des sculptures dans la cavité qui renvoie au modèle traditionnel des mises au tombeau. La figure féminine, de trois quarts, placée sur l'axe médian, forme avec le gisant un triangle, faisant écho avec certains exemples de pietà abordées plus avant. Le monument aux morts de Cuincy (Nord) ressemble beaucoup à celui de Soubès. Un second monument signé Dardé à Clermont-l'Hérault reprend l'idée d'un groupe sculpté - une femme veille un soldat gisant - dans une cavitée ${ }^{46}$. Ici, rien de religieux, alors qu'à Soubès, une croix dans une feuille d'acanthe surmonte le fronton du monument au dos duquel sont gravés ces vers de Victor Hugo "Ceux qui pieusement sont morts pour la Patrie ont droit qu'à leur tombeau la foule vienne et prie $»^{47}$; le monument de Clermont-l'Hérault confond, selon la notice de la base Palissy ${ }^{48}$, la figure féminine ailée de la Victoire avec une danseuse de music-hall. En effet, la figure qui accompagne le poilu n'est que très peu vêtue, sa poitrine transparaît sous le léger voile qui recouvre son corps, et son attitude lascive et ambiguë interpelle tout autant que les plumes de meneuse de revue, censées symboliser les ailes d'un ange, ainsi que la proéminence et la position des seins appuyés sur la pierre sur laquelle est allongée cette femme. Cette sculpture contraste avec le caractère monumental de l'édifice et son inspiration, à moins qu'il ne s'agisse là d'une interprétation très libre par le sculpteur du thème de Marie-Madeleine, longtemps considérée comme une prostituée repentie, mais aussi premier témoin de la résurrection du Christ. Un troisième monument de Paul Dardé à Lodève (Hérault) réunit un gisant et trois groupes de personnages à son chevet: derrière lui, quatre femmes, devant, deux enfants et sur le côté, une femme en pleurs dont le visage est dissimulét ${ }^{4}$. Là encore, pas de signe religieux, bien que l'attitude de recueillement des protagonistes fait penser à une scène d'ensevelissement telle qu'elle se pratique dans la plupart des cimetières de la République. Ce qui surprend ici, c'est la position du poilu : il repose, les bras le long du corps, sur un plan incliné, comme d'autres gisants de monuments aux morts ${ }^{50}$, non pas les jambes serrées l'une contre l'autre mais largement écartées. C'est aussi de cette manière que Paul Dardé a élaboré la figure du poilu mort à Clermont-l'Hérault.

Après la présentation de ces divers monuments, et avant de conclure avec quelques exemples qui comportent des signes religieux, il faut rappeler que sur le territoire national, d'autres monuments font aussi allusion à des thèmes ou personnages religieux, même si de prime abord, l'iconographie religieuse semble absente : c'est sans doute le cas de celui d'Ibos (Hautes-Pyrénées), inauguré le 11 septembre 1921, qui présente en son centre la figure d'une femme en costume régional et coiffée du capulet bigourdan (fig. 13). 
Figure 13

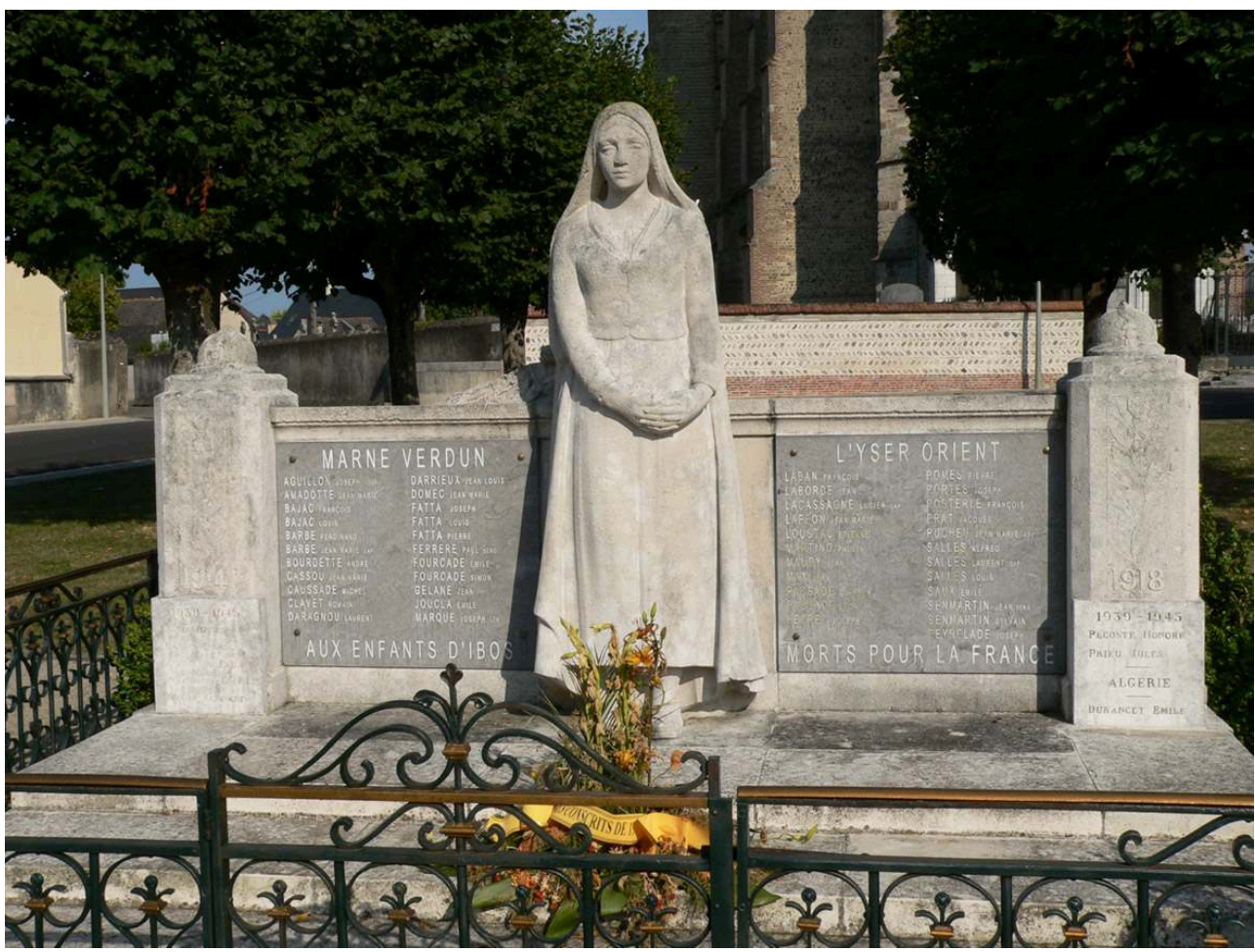

Monument aux morts d'Ibos (Hautes-Pyrénées)

Phot. Dupuis, Claude. (c) Dupuis, Claude, 2009.

L'attitude figée de la jeune veuve mais surtout ses mains croisées rappellent plus la posture de Bernadette Soubirous, comme sur les photographies éditées par Billard et Perrin dès $1863^{51}$, ou bien encore la statue, dans l'église paroissiale de Lourdes, du sculpteur tarbais Firmin Michelet, de celle qui sera déclarée bienheureuse en 1925 avant d'être canonisée en 1933. Michelet est l'auteur de plusieurs monuments aux morts, notamment dans les Hautes-Pyrénées, où apparaît une femme coiffée du capuchon traditionnel et portant un bouquet de fleurs ${ }^{52}$. Il est aussi l'auteur d'une Pietà au poilu, un relief en céramique sur le monument de Bouchavesnes-Bergen, dans la Somme ${ }^{53}$.

\section{Des croix latines dans l'espace public}

Si les auteurs des monuments cités jusqu'ici ont pour la plupart respecté la loi de 1905 puisqu'ils ont seulement fait référence à l'iconographie religieuse sans jamais - ou très rarement - en utiliser les emblèmes, d'autres ont eu recours à des symboles religieux pour des œuvres dans l'espace public. Un document recueilli par Vincent Jochault à propos du monument d'Escoublac met en lumière un phénomène intéressant, celui de l'interprétation de l'article 28 de la loi du 9 décembre 1905, selon laquelle il serait possible d'apposer des emblèmes religieux sur les monuments dès l'instant que ces derniers sont placés en dehors de la voie publique, "c'est-à-dire des rues, places ou routes de la commune $»^{54}$. Un soldat s'effondre, le drapeau national dans les bras, sur une croix nimbée appelée plus couramment croix celtique. Les ornements à caractère religieux peuvent donc être visibles depuis l'espace public communal sans y être 
implantés (fig. 14). Le monument souvent cité de Sillery, dans la Marne, en offre une autre illustration ${ }^{55}$. Situé sur le flanc méridional de l'église, sur le terrain paroissial, il n'en est pas moins visible de tous depuis la place qu'il surplombe. Il se compose d'une pleureuse, agenouillée devant une croix sur laquelle est gravée l'inscription suivante : «Sillery à ses morts glorieux 19141918 ». Quatre autres croix plus petites, réparties de part et d'autre du premier groupe sculpté, portent les noms des disparus, listés par année pour les soldats.

Figure 14

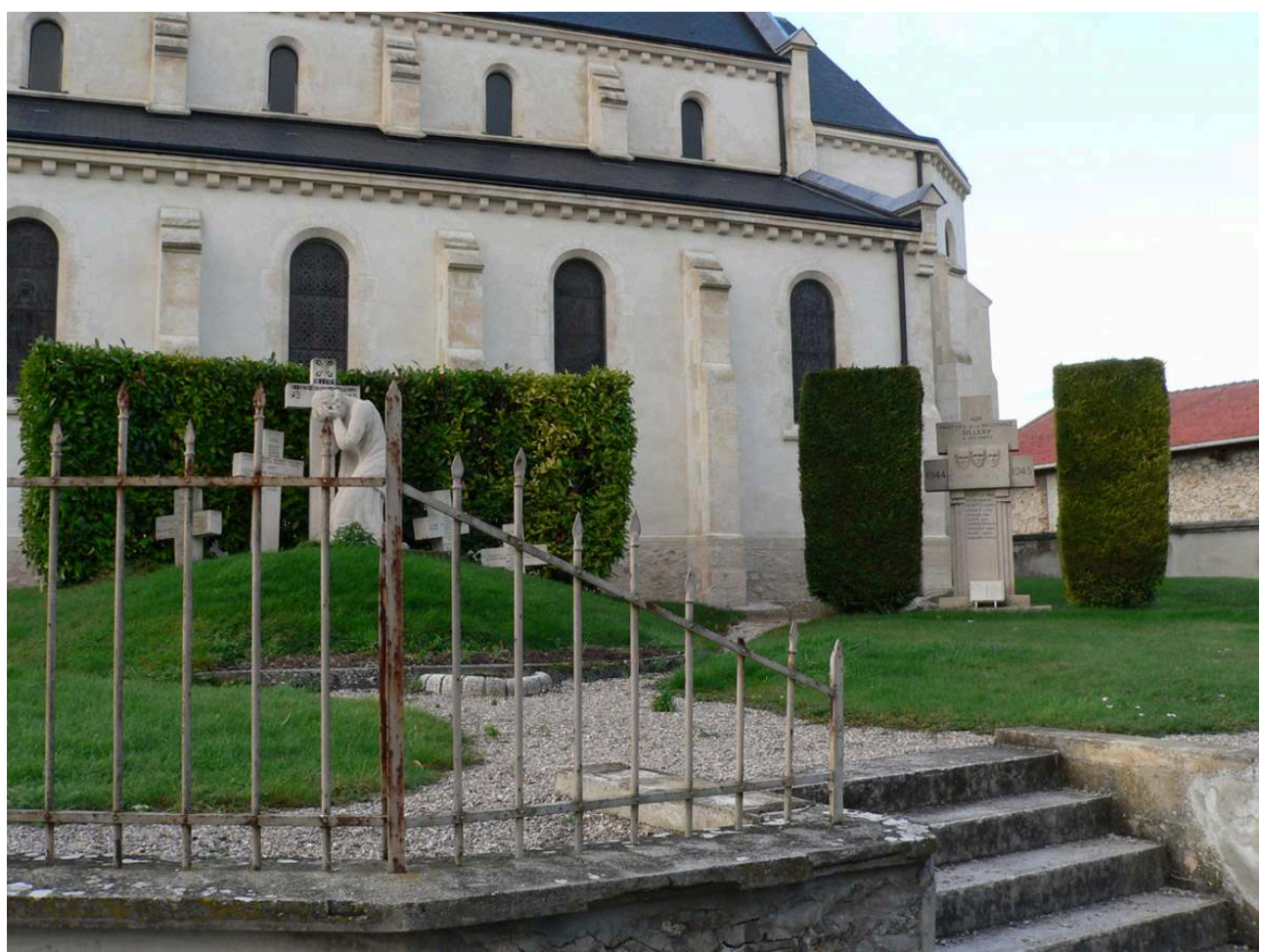

Monument aux morts de Sillery (Marne).

Phot. Dupuis, Claude. (c) Dupuis, Claude, 2009.

Ce qui est valable pour le monument d'Escoublac est donc applicable à d'autres réalisations sur le territoire national. Aujourd'hui, les aménagements de voirie rendent souvent difficile l'appréciation du caractère public ou non de l'espace dédié aux monuments aux morts. C'est le cas à Cuincy, dans la banlieue de Douai, où le monument, dérivé du modèle de la pietà, ne comporte certes pas de signes religieux mais est placé entre l'église et le presbytère, à la frontière même des espaces paroissiaux et publics, une limite matérialisée aujourd'hui encore par des colonnes de pierre. C'est dans ce contexte qu'il faut replacer le monument de Saulty dans le Pas-deCalais (fig. 15). 
Figure 15

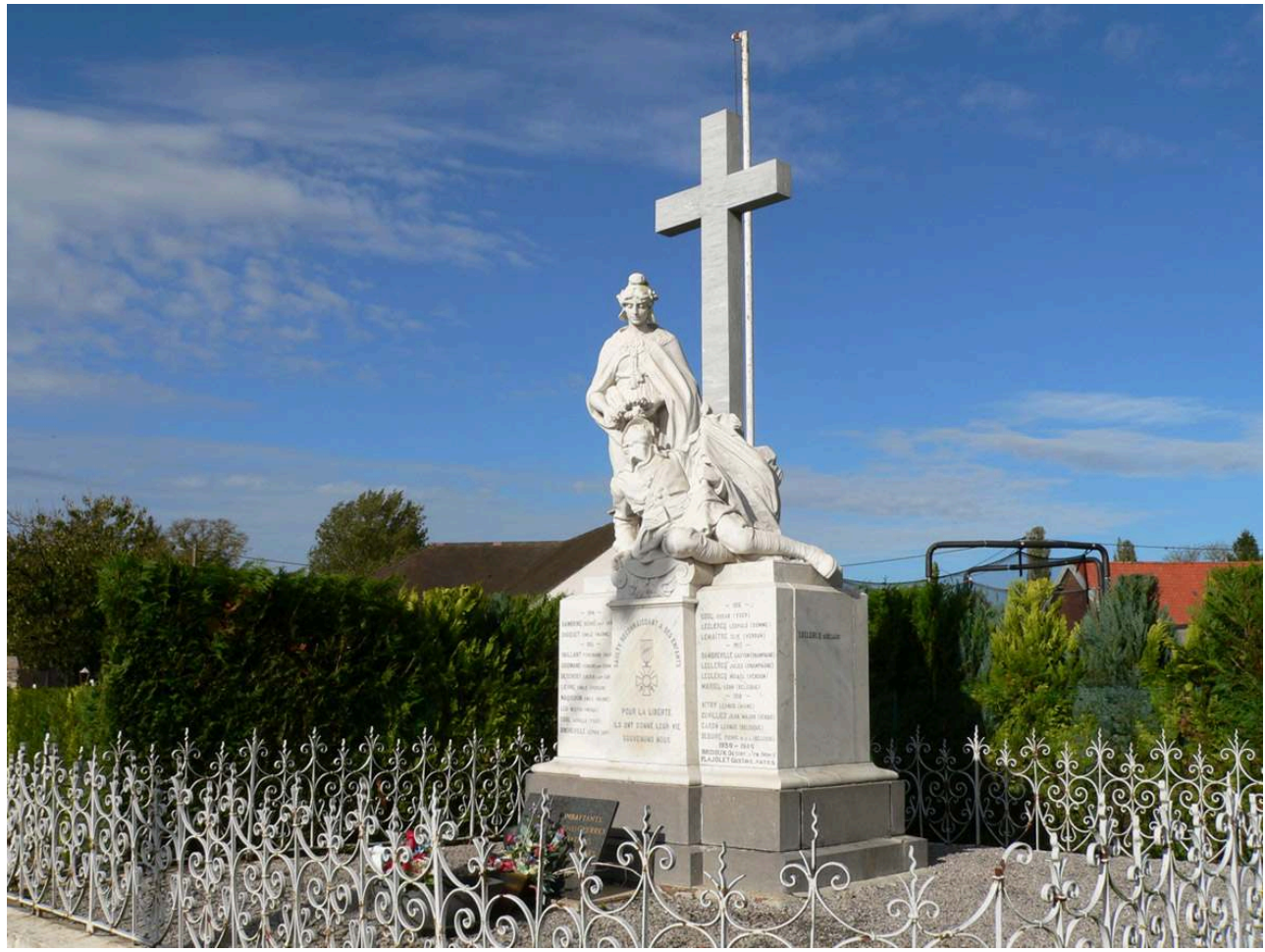

Monument aux morts de Saulty (Pas-de-Calais).

Phot. Dupuis, Claude. (c) Dupuis, Claude, 2013.

Le site Mémoires de Pierre, dont l'ambition est de présenter les monuments aux morts du département, cite l'article du Courrier du Pas-de-Calais du 21 juin 1922 à propos de l'inauguration, le dimanche précédent, du monument de Saulty. L'article se termine ainsi :

Le groupe est dominé par une croix, dont la vue sera toujours, pour les parents des victimes de la guerre, une source de réconfort, en leur donnant l'espérance du revoir dans l'autre monde, et pour les passants, un souvenir du sacrifice suprême accompli par nos héros de la guerre qui se sont, à leur manière, identifiés à la Divine victime du Calvaire... [...] CEuvre de maître, en marbre de Carrare, érigée sur une propriété privée, en bordure de la route, il perpétuera la mémoire des enfants du pays morts à la grande guerre ${ }^{56}$.

Le monument est situé à l'angle de la place publique et de la route départementale D23e1 dans un enclos fermé par une grille métallique de faible hauteur. Il n'est ni dans l'axe de la mairie, ni de l'église comme c'est souvent le cas. Il en est néanmoins à proximité. Dominé par une croix latine monumentale en pierre grise, le poilu reçoit de la France, allégorie féminine portant le bonnet phrygien, une couronne de lauriers alors que son regard semble plus tourné vers la croix que vers la figure de la Nation. Le groupe sculpté dans ce marbre blanc contraste avec la croix par les matériaux mais aussi par sa symbolique républicaine et civile. Le monument de Saulty est du point de vue iconographique un compromis, qui ainsi s'adresse à tous. Son érection sur un terrain privé ne le met pas hors-la-loi, même si comme le souligne l'article déjà cité, nul ne peut échapper à la vision de la croix monumentale alors qu'au monument de Mazan, érigé place du 11 Novembre, sur l'espace communal, la petite croix discrète au cou de la figure féminine est contraire au texte de loi. Sans la présence 
de la croix, le monument de Saulty eut été rangé parmi les nombreux autres d'inspiration religieuse dont il a été question dans la première partie.

Si à Busnes (Pas-de-Calais), le monument aux morts avec ses deux obélisques dont les faces antérieures portent des croix latines gravées, et surtout sa statue de Vierge à l'Enfant, paraît aller à l'encontre du texte de la loi du 9 décembre 1905, il a été érigé dans l'ancien cimetière, aujourd'hui transformé en square public. Ces exemples démontrent la difficulté d'estimer de nos jours, c'est-à-dire près de 90 ans après son érection, le caractère public ou non de l'espace commémoratif marqué par le monument aux morts communal. Aujourd'hui, les polémiques qui ont pu exister sur le caractère religieux ou non de certains monuments ont presque entièrement disparu, même si ces derniers restent considérés par une partie de la population comme quasi sacrés. Dans le cadre d'aménagement de voirie, il est quelquefois nécessaire de déplacer le monument aux morts. Certaines communes doivent alors faire face aux réticences et doléances de leurs concitoyens, comme en 2000 à Escoublac ${ }^{57}$, ou s'accorder avec les associations "patriotiques " locales à l'exemple de Pontchâteau, en Loire-Atlantique, en $2011^{58}$. Dans un éditorial de 2010 du site droitdesreligions.net, les auteurs sont revenus sur la possibilité d'apposer un emblème religieux sur un monument aux morts avec celui de Fontenelle, dans le département de la Côte-d'Or ${ }^{59}$. Une plainte avait été déposée en 2007 contre la délibération du conseil municipal de Fontenelle de déplacer le monument aux morts de l'espace religieux vers l'espace public de la commune, celuici étant surmonté d'une croix latine avec l'inscription « Dieu - Patrie». Le monument ayant été jugé comme funéraire par les tribunaux, rien ne s'oppose à ce qu'il soit orné de motifs religieux, comme l'autorise la loi ${ }^{60}$. Dans le département proche du Doubs, une trentaine de communes possèdent hors cimetière un monument commémoratif orné d'une croix, latine ou nimbée, en relief ou sommitale ${ }^{61}$. Deux d'entre eux accueillent aussi une sculpture de Jeanne d'Arc, un autre une représentation de saint Christophe. Cette situation se répète probablement dans nombre d'autres départements. D'après Annette Becker, dans les régions les plus pieuses, beaucoup de monuments aux morts ont été érigés dans les cimetières afin de pouvoir recevoir des emblèmes religieux ${ }^{62}$.

Le monument atypique de Saint-Rémy-au-Bois (Pas-de-Calais) présente un soldat rescapé appuyé sur son Lebel devant la tombe fraîchement recouverte d'un de ses camarades, à la tête de laquelle se dresse une croix latine coiffée d'un casque Adrian ${ }^{63}$. L'inscription sur le mur derrière l'ensemble " hodie mihi cras tibi ${ }^{64}$ souligne s'il en était besoin le thème de la disparition retenu pour ce monument tardif, inauguré en 1935 : "Enterrer et consoler ", pour paraphraser Annette Becker ${ }^{65}$. Le motif du poilu qui se recueille devant la sépulture d'un soldat mort au combat est aussi rare dans la presse que dans l'iconographie des monuments aux morts ${ }^{66}$, même si d'après l'historienne, "dans la conception de ces monuments [...] on retrouve bien cette volonté de mêler le culte des morts de la guerre à une affirmation de la foi $»^{67}$. Intitulée " les tombes dans les blés» et présentée en couverture de L'Illustration du 31 juillet 1915, la "photographie" de sépultures marquées d'une croix à laquelle est accrochée une couronne de blé est une des rares représentations de ce thème dans l'hebdomadaire durant les années de guerre ${ }^{68}$. C'est peut-être ce désir de syncrétisme qui avait été concrétisé dans le monument provisoire de Gerbéviller (Meurthe-et-Moselle) dont une photographie est parue le 4 septembre 1915 dans le numéro 3783 de L'Illustration ${ }^{69}$. D'après la légende, le cliché représente Mgr. Ruch, coadjuteur de l'archevêque de Nancy 
et aumônier en chef, prononçant une allocution devant le monument constitué d'une simple croix latine ancrée dans un bloc de pierre, l'ensemble reposant sur un socle maçonné. Quelques mois plus tard paraît en double page une photographie dans un style quasi pictorialiste avec au premier plan une croix monumentale élevée sur un monticule de pierre, au milieu de croix de bois avec à l'arrière-plan un prêtre accompagné de nombreux soldats ${ }^{70}$. Au-dessus du sommaire du numéro de Noël du 18 décembre 1915 de la même revue, une composition de Lucien Jonas illustre les paroles " Trois anges sont venus ce soir ... ». Une infirmière apporte un bol à un soldat sur un brancard pendant qu'au fond, deux figures allégoriques apportent une croix de guerre et une couronne de lauriers. Par le biais d'un jeu d'ombre, le lecteur perçoit que la croix de guerre s'adresse à un second soldat blessé, le bras gauche soutenu par une écharpe. Cette composition s'apparente à celles qui, après-guerre, orneront les monuments aux morts. Néanmoins ne se retrouve dans les différents numéros parus entre 1915 et 1917 aucun motif évoqué plus haut, à l'exception d'une figure de poilu portant dans sa main droite une petite Nikê et un canif dans sa main gauche. Le dessin à la symbolique très forte du poilu artisan de la victoire par « Dangon, soldat téléphoniste du génie $»^{71}$ a servi pour l'affiche du salon des Armées de 1917, un salon réservé aux artistes du front ${ }^{72}$.

Du dépouillement des numéros de L'Illustration parus entre 1915 et 1917 ressortent deux pratiques iconographiques : d'un côté, la photographie met en scène des soldats dans une situation souvent figée, ce qui est sans doute dû aux contraintes techniques, et de l'autre, les dessins ou peintures illustrent la vie quotidienne au front ou à l'arrière, dans les familles. Le caractère statique des sculptures de poilus, à l'exception du soldat brandissant son fusil d'Eugène Bénet - le poilu victorieux -, est dans une certaine mesure le reflet de ces images publiées et à usage plutôt collectif. A contrario, les autres scènes rencontrées sur les monuments se réfèrent aux images proposées par les affiches, les dessins ou autres cartes postales ${ }^{73}$ qui, bien que diffusées en grand nombre, s'adressent à chacun de manière plus individuelle, un espace privé dans lequel la religion peut s'exprimer.

\section{La Loi du 9 décembre 1905 respectée}

31 En théorie, la loi sur la Séparation des Églises et de l'État obligeait les édiles communaux à n'accepter que des projets de monuments commémoratifs honorant les soldats morts pour la France ne comportant aucun signe ou emblème religieux. Les nombreux exemples rapportés ici ont pour but d'illustrer les stratégies adoptées par les uns ou les autres pour contourner cet interdit, afin de satisfaire la majorité de leurs concitoyens et électeurs. Du point de vue purement juridique, aucun monument n'est vraiment hors-la-loi, d'autant que celle-ci est diversement interprétable. Il est pourtant indéniable que le sentiment religieux déjà fortement inscrit dans la population s'est intensifié dans cette période troublée, pendant laquelle de nombreuses personnes cherchèrent un réconfort dans la foi. Des différentes modalités de contournement (érection sur un terrain privé mais facilement accessible, recours au caractère funéraire et sépulcral du monument...), c'est l'adaptation d'un sujet religieux au contexte public et laïc de la république qui interpelle par le fait qu'il use presque exclusivement de figures féminines. Des deux analogies qui se constatent dans de nombreuses illustrations, celle entre le Christ et le soldat et celle de Marie avec la 
veuve ou la mère éplorée, seule cette seconde se retrouve sur les monuments aux morts. À qui s'adressent toutes ces réalisations dont la décision à tous les niveaux (communal, départemental ou national) revint à des comités ou commissions essentiellement composés d'hommes ? Est-ce réellement, comme il a été écrit plus haut, pour rendre hommage aux femmes qui ont, en leur qualité de mère ou d'épouse, en plus de l'effort de guerre, subi la perte de leurs proches? Le monument aux morts d'Équeurdreville, aujourd'hui Équeurdreville-Hainneville dans la Manche, est signé Émilie Rolez. Il est l'un des rares en France, le seul actuellement à notre connaissance, à avoir été réalisé par une femme ${ }^{74}$. La complexité des situations et leur nombre important, au-delà de 36000 pour les monuments en général, certes plus réduit pour les monuments figurés et encore plus pour ceux qui font référence à des thèmes religieux, ne permet pas, dans l'état actuel de la recherche, d'apporter une réponse satisfaisante à cette question importante de la réception et du public des monuments aux morts.

\section{NOTES}

1. - Inauguré seulement en 1923, le monument combinant les deux modèles les plus diffusés n'est pas à considérer comme un objet promotionnel, un grand nombre de monuments ayant déjà été réalisés depuis la fin de la guerre.

2. - Voir le site de l'Assemblée nationale: www.assemblee-nationale.fr/histoire/eglise-etat/ sommaire.asp\#loi (consulté le 07/11/13).

3. - RAGON, Michel. L'espace de la mort. Essai sur l'architecture, la décoration et l'urbanisme funéraire. Paris : Albin Michel, 1981, p. 123.

4. - BECKER, Annette. Les monuments aux morts. Mémoire de la Grande Guerre. Paris: Éditions Errance, 1988.

5. - Voir le site www.pedagogie.ac-nantes.fr/80873293/0/fiche__ressourcepedagogique/ (consulté le 07/11/13).

6. - Un autre exemplaire de ce monument se trouve dans le cimetière de Béthencourt dans le département du Nord.

7. - Un monument semblable a été érigé à Saint-Romain-de-Colbosc en Seine-Maritime. Seule manque la Nikê. À Saint-Laurent-de-Brèvedent dans le même département, le monument aux morts se compose uniquement du soldat agonisant placé sur un piédestal parallélépipédique, tel un tombeau moyenâgeux. C'est le même modèle, mais cette fois en bronze, que sa famille a choisi pour commémorer le capitaine Émile Claisse, tué devant Verdun le 22 février 1916. Le monument est privé et érigé dans le cimetière de Caudry dans le département du Nord. Voir la Base de données de monuments aux morts, Institut de Recherches Historiques du Septentrion (IRHIS), http://monumentsmorts.univ-lille3.fr/monument/1808/caudry-presdeleglise/ (consultée le 11/10/2013). Voir, dans ce numéro, l'article de Martine Aubry et Matthieu de Oliveira : Une base de données sur les monuments aux morts : histoire concrète et valorisation numérique.

8. - C'est ainsi qu'en 2007 Françoise Reynier a légendé la vue générale du monument. La notice accompagnant une seconde photographie de l'auteur fait référence à la figure féminine, une « mère vue de face, elle est traitée à la manière d'une Piéta ». Voir sur la base Mémoire : notices MHR93_20108401006 et MHR93_20108401007. 
9. - Voir sur la base Joconde, notice M5037010394.

10. - À propos de l'iconographie du Vœu de Louis XIII, voir MINOIS, Léo. « Le vœu de Louis XIII et la naissance de Louis XIV : observations iconographiques sur la célébration du roi très chrétien ». Les Cahiers de Framespa [En ligne], 11 |2012, mis en ligne le 23 novembre 2012, consulté le 10 octobre 2013. URL : http://framespa.revues.org/2009.

11. - Quelques exemples de communes possédant un monument sur un modèle de pietà « classique »: Privas (Ardèche), Valentigney (Doubs), Saint-François (Guadeloupe), La BauleEscoublac (Loire-Atlantique), Bavay (Nord), Royon (Pas-de-Calais), Arconsat (Puy-de-Dôme), Beaumont, Bouchavesnes-Bergen, Bouchoir, Hamel (Somme).

12. - En effet c'est toujours l'État français qui organise les cultes catholique, luthérien, réformé et israélite dans les deux départements alsaciens et celui de la Moselle.

13. - BECKER, Annette. Les monuments aux morts de la Grande Guerre. Voir le site : www.histoireimage.org/site/etude_comp/etude_comp_detail.php?i=643 (consulté le 14/10/2013).

14. - Voir sur la base Mérimée : notice IA00024337.

15. - Le monument aux morts de Thann a été inauguré le 11 novembre 1951. Voir le site: http:// www.ville-thann.fr/Decouvrir-Thann/Histoire/Les-chemins-de-la-memoire\#Monument 20chardon (consulté le 29/08/2014).

16. - Voir sur la base Mérimée : notice IA00035482.

17. - D'autres réalisations de Real del Sarte affichent des signes ou symboles religieux dans l'espace public à l'exemple du monument aux morts de la ville de Sceaux, dans les Hauts-de-Seine (base Mérimée : notice IA00119733) ou de celui de Besse-sur-Issole dans le Var (base Mérimée : notice IA00127194).

18. - Maxime Real del Sarte est l'auteur de nombreuses statues de Jeanne d'Arc, béatifiée en 1909 et canonisée en 1920, dont celle de Jeanne au bûcher sculptée en 1928, aujourd'hui place du Vieux-Marché à Rouen et inscrite au titre des Monuments historiques le 30 octobre 2002 (base Mérimée: notice PA76000060). Deux répliques furent réalisées en 1944 et 1948 pour respectivement l'université de Montréal au Québec et la ville de Buenos Aires en Argentine. Le motif apparenté à celui des pietà à Briey ou à Sommières-du-Clain a été plusieurs fois travaillé par Real del Sarte comme en témoigne le monument de 1935 à la mémoire du 106 régiment d'infanterie aux Éparges, dans la Meuse, où une femme casquée porte dans ses bras un soldat mort. C'est là même où le sculpteur fut blessé en 1916 avant d'être amputé de l'avant-bras gauche. La main sculptée dans la pierre y fait référence. Maurice Genevoix a souvent écrit sur la bataille des Éparges en 1915, il était alors lieutenant au 106 régiment d'infanterie. Il y fut aussi blessé. La citation de l'auteur gravée sur le monument fait elle aussi référence aux mains (base Mérimée : notice IA00036468).

19. - Aujourd'hui cinq monuments intitulés Je t'ai cherché ont été repérés sur le territoire français, trois en bronze : au cimetière du Tréport en Seine-Maritime, accolé au chœur de l'église de Sare dans les Pyrénées-Atlantiques et à Saint-Chély-d'Apcher en Lozère sur le Foirail entre l'église et la mairie. Deux versions en pierre ont été érigées à Ressons-sur-Matz dans l'Oise et sur le côté de l'église Saint-Pierre-et-Saint-Paul à Cérisy-la-Salle dans la Manche.

20. - La maquette du projet réalisé en 1922 est aujourd'hui conservée au musée de Brou (inv. 968.99) à Bourg-en-Bresse (notice 09630001636, base Joconde).

21. - Voir le site: http://monumentsmorts.univ-lille3.fr/monument/112/bois-grenierpresdeleglise/ (consulté le 29/08/2014).

22. - Voir sur la base Mérimée : notice PA10000029.

23. - Base de données de monuments aux morts, Institut de Recherches Historiques du Septentrion (IRHIS), http://monumentsmorts.univ-lille3.fr/monument/219/crespinpresdeleglise/ (consultée le 07/11/2013).

24. - Voir sur la base Mérimée : notice IA00140978.

25. - Voir sur la base Palissy : notice PM87000734. 
26. - Les exemples suivants sont à notre avis aussi dérivés de l'iconographie religieuse (pietà, déploration, stabat mater...): Mézières-sur-Oise (Aisne), Valensole (Alpes-de-Haute-Provence), Belcaire (Aude), Saint-Geniez-d'Olt (Aveyron), Lambesc, Tarascon (Bouches-du-Rhône), SaintMartin-Valmeroux (Cantal), Saintes (Charente-Maritime), Corseul (Côtes-d'Armor), Dreux (Eureet-Loire), Nogent-le-Rotrou (Eure-et-Loir), Flornoy, Roquemaure (Gard), Langres (Haute-Marne), Saint-Jean-de-Fos (Hérault), Fumel (Lot-et-Garonne), Morez (Jura), Saint-Martin-d'Arcé (Maineet-Loire), Le Lorrain, Macouba (Martinique), Bonzée, Dannevoux, Sassey-sur-Meuse, Sténay (Meuse), Cuincy, Laventie, Sin-le-Noble (Nord), Écourt-Saint-Quentin, Vermelles (Pas-de-Calais), Aubières, Chamalières, Chatel-Guyon, Saint-Anthème (Puy-de-Dôme), Airaines, Long, Rue (Somme).

27. - Voir sur la base Mérimée : notice IA18000077.

28. - Sur le relief central du monument aux morts de Mandeure (Doubs), deux soldats, l'un debout soutenant le second, sont représentés. Cette composition rappelle celle des monuments de Lamballe et de Lannion (Côtes-d'Armor). Une représentation plus proche du motif de la pietà, c'est-à-dire d'un corps inanimé reposant sur les genoux d'une femme se retrouve sur le monument du cimetière tchèque de La Targette, sur la commune de Neuville-Saint-Vaast dans le Pas-de-Calais. Voir les sites: http://www.cheminsdememoire.gouv.fr/; http:// www.cheminsdememoire-nordpasdecalais.fr/visiter-les-sites/le-front/memorial-de-lacompagnie-nazdar-et-cimetiere-tchecoslovaque-neuville-saint-vaast.html (consulté le 29/08/2014).

29. - Site des archives municipales de Saint-Étienne : http://www.archives.saint-etienne.fr/site/ index.asp?rubrique=tranchesHistoire\&el_id=240.

30. - Cette composition du soldat sur un socle plus haut que les figures qui l'accompagnent a aussi été employée par Pierre Curillon à Paray-le-Monial. En contre-bas de la sculpture du soldat, monument érigé après la guerre de 1870 , il a placé d'un côté un groupe sculpté représentant l'Alsace et la Moselle repassées sous le giron français et de l'autre, un poilu.

31. - Voir la note $n^{\circ} 19$.

32. - Il présida la commission départementale d'examen des projets d'érection de monuments commémoratifs aux morts de la Guerre dans la Somme créée en 1920. Voir l'enquête Les monuments aux morts de la Première Guerre mondiale dans la Somme sur le site de l'Inventaire $\mathrm{du}$ Patrimoine Culturel de Picardie: http://inventaire.picardie.fr/docs/ MERIMEEIA80000113.html?qid=sdx_q0.

33. - L'attribution du buste au statuaire Roze découle entre autres de la comparaison avec le visage du soldat de la jeune génération sur le monument de Montdidier dans la Somme ; voir sur la base Palissy : notice IM80000044, sur la base Mérimée : notice IA80000064.

34. - L'obélisque, dont le pyramidion a été remplacé par un pot à feu, a été, selon la date portée sur le monument, inauguré le 27 juillet 1924 alors que la statue de la pleureuse porte la date de 1925 ; voir sur la base Palissy : notice IM80000008, sur la base Mérimée : notice IA80000034.

35. - Voir le site: http://archives.somme.fr/ark:/58483/a011308867881zAql7C (consulté le 29/08/2014).

36. - Un motif similaire est visible sur le relief latéral gauche du monument aux morts de Proyart (Somme) inauguré le 28 septembre 1924. Intitulée Le départ, la scène présente un soldat qui embrasse sa femme sur le front sous le regard d'une femme plus âgée et celui d'un enfant qui tente d'attirer l'attention de son père. Voir sur la base Palissy : notice IM80000052, sur la base Mérimée : notice IA80000057.

37. - Voir sur la base Palissy : notice IM80000973.

38. - Voir le site : http://archives.somme.fr/ark:/58483/a011308867881yLp9lf; voir sur la base Palissy : notice IM80000033, sur la base Mérimée : notice IA80000009. 
39. - Le tombeau d'Évrard de Fouilloy était « placé autrefois à l'entrée de la nef, dans l'axe [...]». VIOLLET-LE-DUC, Eugène-Emmanuel. «Tombeau». Dans Dictionnaire raisonné de l'architecture française du XIe au XVI siècle, Tome 9. Paris : B. Bance / A. Morel, 1854-1868, p. 61-62.

40. - Voir le site : http://inventaire.picardie.fr/docs/PALISSYIM80000973.html.

41. - À titre d'exemples de figures paternelles : à Amiens, le groupe sculpté du "premier né » à l'entrée de l'hôpital nord, le fronton de l'ancienne Caisse d'Épargne rue de la République, le monument Le pardon au conservatoire national de musique, le relief en bronze La famille, aujourd'hui dans le salon d'honneur du conseil régional de Picardie.

42. - Voir dans la base Mérimée : notice IA80000036; et le site : http://archives.somme.fr/ark:/ 58483/a011308867881XQ9Zql.

43. - Voir dans la base Mérimée : notice IA80000035.

44. - C'est probablement la raison pour laquelle le monument est désigné par l'Inventaire comme « allégorie du deuil et du renouveau »; voir sur la base Palissy : notice IM80000033.

45. - Voir sur la base Palissy : notice IM34001690, sur la base Mérimée : notice IA00029607.

46. - Voir sur la base Palissy : notice IM34001686, sur la base Mérimée : notice PA34000032.

47. - HUGO, Victor. Les Chants du Crépuscule, Hymne. 1831. Ces vers se retrouvent sur d'autres monuments aux morts du territoire français : à Airaines (base Mérimée : notice IA80000031, et base Palissy : notice IM80000002) et Équancourt dans la Somme. Une version plus longue orne le monument de la ville de Nîmes (Gard) : «Ceux qui pieusement sont morts pour la Patrie ont droit qu'à leur tombeau la foule vienne et prie. Entre les plus beaux noms leur nom est le plus beau, la voix du peuple entier les berce en leur tombeau » (base Palissy : notice IM30000419).

48. - Voir sur la base Palissy : notice IM34001686.

49. - Voir sur la base Mérimée : notice PA34000033.

50. - Pacé (Ille-et-Vilaine), Commensacq (Landes), Pontfaverger-Moronvilliers (Marne), Richebourg (Pas-de-Calais), cimetière de Maisons-Laffitte (Yvelines)...

51. - Voir PELLERIN, Denis. «Les lucarnes de l'infini ». Études photographiques, 4 | Mai 1998, [En ligne], mis en ligne le 18 novembre 2002. URL : http://etudesphotographiques.revues.org/156 (consulté le 3 novembre 2013).

52. - Andrest, Luz-Saint-Sauveur, Rabastens, Tournay (Hautes-Pyrénées).

53. - Voir sur la base Mérimée : notice IA80000049, sur la base Palissy : notice IM80000017.

54. - Voir JOCHAULT, Vincent. Le monument aux morts d'Escoublac - La Baule (4), Doc 15. : Réponse du ministre de l'Intérieur à une question d'un Député, concernant les emblèmes religieux sur les monuments aux morts. [En ligne], mis en ligne le 8 novembre 2008. URL: http:// www.pedagogie.ac-nantes.fr/80873293/0/fiche_-_ressourcepedagogique/\&RH=PEDA (consulté le 5 novembre 2013).

55. - Voir sur la base Mérimée : notice IA51000568.

56. - Voir le site: http://memoiresdepierre.pagesperso-orange.fr/alphabetnew/s/saulty.html (consulté le 5 novembre 2013).

57. - Voir note 52.

58. - Une croix en ronde-bosse orne le socle de ce monument. En 2011 le monument a été déplacé après une concertation avec « les associations à caractère patriotique » selon le quotidien OuestFrance : http://www.ouest-france.fr/le-monument-aux-morts-sera-deplace-lundi-pour-ladeuxieme-fois-depuis-1923-124734 (consulté le 5 novembre 2013).

59. - Voir le site : http://www.droitdesreligions.net/edito/edito04_2010.htm\#_ftn1 (consulté le 5 novembre 2013).

60. - «Considérant, en premier lieu, qu'il résulte de la distinction même faite par le législateur entre les terrains de sépulture dans les cimetières et les monuments funéraires, que cette dernière expression s'applique à tous les monuments destinés à rappeler le souvenir des morts, même s'ils ne recouvrent pas de sépultures et quel que soit le lieu où ils sont érigés; que, dès lors, contrairement à ce que soutient $\mathrm{M}$. A, le monument élevé à la mémoire des morts de la guerre de 
1914-1918, initialement sur un emplacement situé devant l'église de ladite commune, doit être considéré comme un monument funéraire au sens des dispositions précitées de l'article 28 de la loi du 9 décembre 1905, nonobstant la circonstance qu'il n'a pas été érigé dans un cimetière ; que, par suite, l'apposition de signes ou emblèmes religieux sur ce monument n'était pas interdite par cet article » : http://www.droitdesreligions.net/juris/caa/caa_lyon_07ly02583_16032010.htm.

61. - (Sous réserve) : Amathay-Vésigneux, Arc-et-Senans, Bretonvillers, Bolandoz, Boujailles, Bouverans, Buffard, Bulle, Cernay-L'Église, Dommartin, Dompierre-Les-Tilles, Durnes, Évillers, Fuans, La Grange, La Rivière-Drugeon, Les Fontenelles, Les Fourgs, Levier, Liesle, Longeville, Remoray-Boujeons, Sombacour, Trévillers, Vaux-et-Chantegrue, Vernierfontaine, Vuillafans, Vuillecin. Le caractère public et la propriété des terrains accueillant les monuments des communes de la liste précédente n'ont pu être vérifiés. De nombreuses autres communes du Doubs possèdent elles aussi des monuments décorés de croix latine, mais leur situation à proximité des édifices religieux, même terrain ou enclos, font qu'elles n'apparaissent pas dans le cadre présent.

62. - «Dans l'Ouest très catholique, en Alsace, en Lorraine, plus de monuments ont été érigés dans les cimetières ou enclos paroissiaux que dans le reste de la France, pour que leurs populations puissent christianiser à loisir leur monument ». BECKER, Annette. La guerre et la foi. De la mort à la mémoire 1914-1930. Paris : Armand Colin, 1994, p. 118.

63. - Le motif similaire de la croix surmontée du casque se retrouve sur le socle du monument aux morts de Châteauneuf-d'Ille-et-Vilaine. Une croix aux branches plus larges et sommée d'un casque émerge du tertre de terre sur lequel se dresse le poilu du monument de Baugé (Maine-etLoire). Dans un esprit similaire il faut citer deux monuments auvergnats : celui du Cheix-surMorge (Puy-de-Dôme), un soldat se dresse devant une croix alors qu'à Tauves, dans le même département, une femme coiffe d'une couronne de lauriers une croix basse, symbolisant la sépulture des combattants de la commune. Le symbole du soldat mort représenté par cette croix à laquelle le casque désormais inutile est suspendu apparaît sur de nombreux monuments, même si c'est quelquefois de manière discrète. À Don (Nord), la masse imposante du groupe sculpté fait oublier ce détail, d'autant plus que des chardons couvrent en partie cette croix. D'autres exemples à Presles-et-Boves (Aisne), Boisse-Penchot (Aveyron), Gradignan, Le Teich (Gironde), Ganges (Hérault), Suippes (Marne) et Douzies-Montplaisir aujourd'hui rattaché à Maubeuge (Nord).

64. - « Aujourd'hui c'est moi, demain ce sera toi ».

65. - Voir BECKER, Annette (1994), op. cit., p. 105.

66. - Deux objets de la collection de l'Historial de Péronne montrent que ce sujet est universel, communs aux diverses nations en conflit. Une maquette de monument aux morts des années 1921-1925 signée du britannique Charles Sargeant Jagger met en scène un soldat qui se recueille devant une tombe marquée d'une croix (inv. 017900). Une assiette en céramique d'origine allemande présente une scène similaire au monument de Saint-Rémy-au-Bois intitulée Ich hatt'einen Kameraden [J'avais un camarade] (inv. 000118).

67. - BECKER, Annette (1994), op. cit., p. 117.

68. - L'hebdomadaire publiera en 1917 deux photographies des funérailles du lieutenant Richard, tombé en Roumanie. Ces représentations sont rares, seules les funérailles de personnalités sont présentées. Les cadavres photographiés sont principalement ceux de soldats ennemis, sauf pour l'année 1915 où des poilus morts apparaissent encore avant de disparaître les deux années suivantes. L'Illustration, 3876, 16 juin 1917, p. 557.

69. - L'Illustration, 3783, 4 septembre 1917, p. 256.

70. - L'Illustration, 3797, 11 décembre 1915, p. 620-621.

71. - L'Illustration, 3856, 27 janvier 1917, p. 80.

72. - « Le salon des armées », L'Illustration, 3854, 13 janvier 1917, p. 39. 
73. - Différentes institutions ont utilisé les cartes postales pour financer leur action auprès des soldats, des familles et des orphelins : les motifs religieux y sont légion.

74. - Voir sur la base Mérimée : notice EA50000011. Le monument d'Émilie Rolez à Équeurdreville fait, avec celui réalisé en 1932 d'après un plâtre de Käthe Kollwitz pour le cimetière militaire allemand de Vladslo près de Dixmude/Diksmuide en Belgique fait figure d'exception dans ce domaine au niveau européen. Voir le site: http://www.kollwitz.de/fr/lebenslauf.aspx, http:// centenaire.org/fr/autour-de-la-grande-guerre/photographie/photographie-artistique/labelgique-dans-les-photographies (consulté le 7 novembre 2013).

\section{ABSTRACTS}

After the French law of December 1905 separating the Church and the State, monuments erected in the public realm were supposed to be entirely devoid of religious symbolism and war memorials were not exempted from this rule. Yet many sponsors and artists managed to get round this ban. In particular by using the female figure, sculptors often succeeded in introducing a religious element into their creation. This article takes a look at a selection of war memorials scattered throughout France in order to see how references to themes of a religious nature were used, either respecting the principle of secularism or subverting it.

Depuis la loi de Séparation des Églises et de l'État de décembre 1905, aucune réalisation dans l'espace public ne peut comporter de symbole religieux. Les monuments aux morts n'échappent pas à la règle. Or, nombre de commanditaires et d'artistes ont contourné l'interdit. C'est principalement par le biais d'une figure féminine que le sculpteur a introduit le religieux dans la scène. C'est à travers une sélection de monuments disséminés dans l'Hexagone que sont étudiées ces reprises et adaptations de thèmes issus du registre religieux, sous la contrainte, respectée ou contournée, de laïcité.

\section{INDEX}

Mots-clés: monument aux morts, loi de Séparation des Églises et de l'État, laïcité, espace public, emblèmes religieux, statuaire, pietà, figure féminine

Keywords: War memorial, law of separation of Church and State, secularism, public realm, religious emblems, statues, Pietà, female figure

\section{AUTHOR}

\section{CLAUDE DUPUIS}

docteur en histoire de l'art, Vieux-Moulin, Vosges crp.dupuis@orange.fr 